\author{
KIM B. CLARK \\ Harvard University \\ W. BRUCE CHEW \\ Harvard University
}

TAKAHIRO FUJIMOTO

Harvard University

\title{
Product Development in the World Auto Industry
}

CHANGes in international competition in the past decade, and particularly the competitive problems of once-dominant U.S. firms and industries, have heightened interest in what causes international differences in productivity and product quality. Although analysis of macroeconomic data has produced some important insights, recent research has focused increasingly on the comparative behavior of industries, firms, and factories. ${ }^{1}$ Such research raises in a direct way the issue of management efficiency. Especially at the factory level, a growing body of evidence

This research was supported by the Division of Research, Graduate School of Business Administration, Harvard University. We are indebted to Brandt Goldstein and Frank Dubinskas for their assistance.

1. For an eclectic survey of microeconomic productivity research see Richard R. Nelson, "Research on Productivity Growth and Productivity Differences: Dead Ends and New Departures,"' Journal of Economic Literature, vol. 19 (September 1981), pp. 1029_ 64. Recent examples would include Robert H. Hayes and Kim B. Clark, "Exploring the Sources of Productivity Differences at the Factory Level," in Kim B. Clark, Robert H. Hayes, and Christopher Lorenz, eds., The Uneasy Alliance: Managing the ProductivityTechnology Dilemma (Harvard Business School Press, 1985), pp. 151-88; Bernard Eugene Ichniowski, "How Do Labor Relations Matter? A Study of Productivity in Eleven Manufacturing Plants"' (Ph.D. dissertation, Massachusetts Institute of Technology, 1983); and Benjamin Klotz, Rey Madoo, and Reed Hansen, "A Study of High and Low 'Labor Productivity' Establishments in U.S. Manufacturing," in John W. Kendrick and Beatrice N. Vaccara, New Developments in Productivity Measurement and Analysis (University of Chicago Press for the National Bureau of Economic Research, 1980), pp. 239-86. 
indicates that international differences in internal operations-most notably quality control and inventories-are important in explaining variations in productivity in a number of industries. ${ }^{2}$

In contrast to the work on productivity in plants, there has been little empirical work on the relative performance of international competitors in the introduction of new products. ${ }^{3}$ Yet theory and empirical evidence suggest that such differences may be crucial to competitiveness. In the auto industry, for example, product development accounts for a large part of total investment in research and development and represents a substantial commitment of resources. ${ }^{4}$ In $1986, R \& D$ investment in the United States alone amounted to $\$ 6.25$ billion, much of it devoted to product development. ${ }^{5}$ Of course, the effect of R\&D on a business extends far beyond costs. Advances in technology and product performance enter the marketplace through new products. Product development thus affects customer choice and manufacturing, with consequent effects on productivity, quality, and market share.

In an industry such as automobiles, in which products are differentiated and scale and learning effects are important to production, the timely introduction of a successful new product may yield gains in market share, profit margins, and productivity: the history of the auto industry is replete with such examples. ${ }^{6}$ And the stakes are not trivial. In the

2. Notable discussions include David A. Garvin, "Quality on the Line," Harvard Business Review, vol. 61 (September-October 1983), pp. 64-75; Robert W. Hall, Zero Inventories (Homewood, Ill.: Dow Jones-Irwin, 1983); Robert H. Hayes, "Why Japanese Factories Work," Harvard Business Review, vol. 59 (July-August 1981), pp. 56-66; and Richard J. Schonberger, Japanese Manufacturing Techniques: Nine Hidden Lessons in Simplicity (Free Press, 1982).

3. While much has been written about research and development projects, little of this research explores international differences in development at anything but a macroeconomic level. A recent exception is Hirotaka Takeuchi and Ikujiro Nonaka, "The New New Product Development Game,"' Harvard Business Review, vol. 64 (January-February 1986), pp. 137-46.

4. Private development represents the bulk of R\&D expenditures. Development's share of R\&D in the United States may run as high as 70 percent.

5. National Science Foundation, Research and Development in Industry Annual, 1985 (GPO, 1987).

6. Product development costs and a design's manufacturability will affect production costs. The marketability of the design will affect margins and unit sales, and the project's completion date will influence the timing and number of periods of sale. Together these factors have an impact on market share, profitability, and productivity. For details on the enormous effect of the Model $\mathrm{T}$ on Ford, for instance, see William Abernathy, The 
United States alone, a single percentage point of market share amounted to 114,526 units in 1986. Such volumes have significant implications for costs and profits. ${ }^{7}$

In addition to changes in volume, product development may affect productivity through changes in design, and product designs may have an important effect on yields and costs in production. ${ }^{8}$ Mundane issues like the selection of a fastener or the shape of a plastic piece affect the number of parts, the ease of assembly, and hence the cost of the product. In addition, the ability to exploit the potential for automation in processing often depends on the design of the product.

The impact of new products on costs, productivity, and customer choice suggests that product development may have important competitive implications. Yet, if product designs could be changed instantaneously at low cost, the competitive impact of a new product would be sharply reduced. Thus what gives product development the power to affect competition is the long life of the designs. Depending on the product, changing from one design to another entails significant adjustment costs and time. Moreover, the organizational capabilities that determine the time and costs required-the engineering know-how, the procedures and information systems-are even longer-lived assets with significant costs of adjustment. In an industry such as automobile manufacturing, the life of a given design is measured in years while the life of a development organization may be measured in decades.

Productivity Dilemma: Roadblock to Innovation in the Automobile Industry (Johns Hopkins University Press, 1978). The more recent effect of the Taurus/Sable auto on Ford has been discussed in a number of articles, including James B. Treece and others, "Can Ford Stay on Top?' Business Week (September 28, 1987), pp. 78-86.

7. For market size see Harry A. Stark, "'1986 Review/Preview," Ward's Automotive Yearbook, 1986 (Detroit: Ward's Communications, 1987), p. 13. For a discussion of volume and marginal costs see Clifford Winston and associates, Blind Intersection (Brookings, 1987), chap. 2. There is also a significant impact if designs are late. A very successful vehicle may generate gross revenues of $\$ 7.5$ billion over its life (five years, 200,000 units a year at a wholesale price of $\$ 7,500$ ). Discounted at 10 percent (chosen arbitrarily for illustration), this means $\$ 6$ billion. Simply putting off this revenue by four months because a project is late would discount the present value by almost $\$ 200$ million. This figure is high since it represents revenues rather than profits, but with most of the labor and capital in place at the planned launch date, the lost profits would be perhaps as high as 60 percent of the $\$ 200$ million, or nearly $\$ 1$ million lost for every day the project is delayed.

8. For an overview of literature on "designing for manufacturing," see G. Shirley, "The Management of Manufacturing Flexibility: Studies in the Design Manufacturing Interface" (Ph.D. dissertation, Harvard University, 1987). 
Of course, if the manufacturers are similar and decisions on new products subject to some degree of coordination, product development may not be a central feature of competition and may have less effect on productivity. But the success of innovative Japanese and European products and the mixed record of U.S. competitors in various markets suggest that performance in product development may be important for competitiveness. ${ }^{9}$ The truth of this observation is buttressed by the growing fragmentation of markets, the proliferation of new products, and the increased attention placed on product development by senior executives throughout the world. ${ }^{10}$

This paper presents the initial results of a study of product development in the world auto industry using data on passenger vehicle development projects from twenty automobile companies in Japan, Europe, and the United States. We first characterize and quantify differences among projects in engineering hours and lead time and then explain those differences in terms of the scope and complexity of the project and the way it was organized and managed.

\section{A Model of Product Development}

The unit of analysis in this study is the product development project. New products may simply be those incorporating minor changes to established designs (for example, a washing machine with an almond

9. Foreign entrants to U.S. markets have repeatedly forced established companies to counterattack by developing new products or else lose their competitive positions. This pattern has been seen in the manufacture of radio receivers, automobiles, plain paper copiers, and ceramic packaging for integrated circuits, to name just a few. In recent years the Japanese have played the most dramatic role as new entrants; see Kim B. Clark, "Managing Technology in International Competition: The Case of Product Development in Response to Foreign Entry," in A. Michael Spence and Heather A. Hazard, eds., International Competitiveness (Ballinger, 1988), pp. 27-74.

10. Our data suggest that the total number of vehicle designs has increased in all regional markets. Given the slow growth of these markets, such proliferation has led to reduced volumes per vehicle design, increasing the importance of efficient product development; see Jeffrey Miller, Jinchiro Nokane, and Thomas Vollmann, "The Global Manufacturing Futures Survey," Manufacturing Roundtable Research Report series (Boston University School of Management, 1983). 
cabinet instead of a white one), or they may use new technology to create new markets (the Xerox 914 copier). This study examines new models of an established product in a market in which the firm already competes. But the models may represent an attempt to define a new niche within that market and may involve innovation in components and systems. Product development of this kind is not research; there is no theoretical question to be explored and little uncertainty about technical feasibility. There is uncertainty in development, but it concerns the specific form the product will take, the degree of performance it will achieve, and its acceptance in the market.

We use the idea of information processing to organize the analysis. ${ }^{11}$ In this context product development comprises activities that translate knowledge of market needs and technological opportunities into information for production. The information includes product concepts, styling models, specifications, layouts, prototypes, engineering drawings, process designs, tools and dies, equipment, and software. The product itself is thus a bundle of information embodied in materials.

\section{THE, PRODUCT DEVELOPMENT PROCESS}

Product development constitutes a complex set of activities involving many people for long periods. To give some structure to the problem of evaluating the development process, we developed a simple model. Our starting point was the assumption that development occurs through problem-solving cycles carried out by engineers who attempt to optimize a number of different performance parameters in an uncertain environment. The engineers begin with broad objectives determined through long-range planning. The objectives generally define the target market, including price range, performance parameters, customers, and relationships to other products. Given these objectives, project performance is measured by the quality of the design and its manufacturability as well

11. Information processing has been widely used as a way of organizing thought about innovation; see, for example, Sumner Meyers and Donald Marquis, Successful Industrial Innovations (National Science Foundation, 1969). For a fuller discussion of the information-processing model of auto product development, see Kim B. Clark and Takahiro Fujimoto, "Overlapping Problem Solving in Product Development," working paper 87-048 (Harvard Business School, Division of Research, 1987). 
as development costs and lead time. ${ }^{12}$ Defined in these terms, the project engineers' objective is to meet quality and manufacturability requirements while minimizing cost and lead time. This is no small challenge, especially since for a given level of quality there appears to be a tradeoff between expected cost and expected lead time. ${ }^{13}$

In our framework, there are four major activities in product development: concept generation, product planning, product engineering, and production engineering. ${ }^{14}$ In each, information from a previous activity is used to create new information for a subsequent activity.

Each activity can be divided into a hierarchy of tasks, subtasks, and sub-subtasks. At the base of the hierarchy is the set of activities, the unit tasks, beyond which further decomposition is not attempted. In product development there are two types of unit tasks: engineering and coordination. The times required for completing a unit engineering task and a

12. Quality includes both technical parameters that define the class of vehicle (size, degree of luxury, weight) and its marketability (ride, handling, aesthetics) as perceived by the auto purchaser. Manufacturability refers to the quality of the design as perceived by the factory that will produce the vehicle. In this sense the factory is another customer of the development group. Cost refers to the resources consumed in development, not vehicle unit cost. Lead time is the time elapsed from the start of work on the product concept to market introduction. By some definitions, the technical, marketability, and even manufacturability dimensions are all subcategories of quality. For more on the subject of product quality as a performance parameter see David A. Garvin, "What Does 'Product Quality' Really Mean?" Sloan Management Review, vol. 26 (Fall 1984), pp. 25-43.

13. The notion of a convex time-cost trade-off has been explored both theoretically in F. M. Scherer, "Time-Cost Tradeoffs in Uncertain Empirical Research Projects," Naval Research Logistics Quarterly, vol. 13 (March 1966), pp. 71-82, and empirically in Edwin Mansfield and others, Research and Innovation in the Modern Corporation (Norton, 1971).

14. Concept generation occurs when information on customer needs or problems is translated into a written statement of the product concept. Product planning occurs when detailed targets for performance, cost, and styling are developed from the product concept. Styling is expressed by clay or plastic models; the other targets are written documents. Performance includes not only technical goals such as weight and horsepower but marketability goals such as ride and handling. Product engineering occurs when product targets are translated into a set of detailed engineering drawings. The drawings are backed by engineering prototypes and computer-assisted design data files. Production engineering occurs when engineering drawings are translated into a process design at various levels, such as process flow charts and plant layout, tool and equipment design, work design, and parts programming. The process design information is then transferred to actual elements of the production process, such as tools, equipment, and operator skills, using pilot runs and start-up activities in the factory. 
unit coordination task may be called unit engineering time and unit coordination time. Given the project's organizational structure, these times will depend on the capabilities of the engineers and the ability of the development organization to process information. Unit times are, of course, not predictable with certainty.

Given staffing levels, the sum of the times actually required to perform the unit activities determines the total number of engineering hours used in the project. However, the project's duration, which we will call lead time, is not a simple function of the number of unit tasks and their duration. The elapsed time will also be affected by the way in which the unit tasks are interrelated. They may be executed in parallel, in sequence, or may be partially overlapped to form the total project system. Whether the tasks can be carried out in parallel depends on their nature and the problem-solving capabilities of the organization. ${ }^{15}$

A certain subset of the unit tasks constitutes what has been called the project system's critical path. ${ }^{16}$ Any time added to the critical path through additional sequential tasks or increased unit engineering or coordination time will delay the project's completion. Noncritical parallel paths will also exist. These paths have slack time; time added to them will not delay the project's completion unless so much is added that the slack time is eliminated and the path becomes critical.

The presence of both critical and noncritical sets of tasks implies that there will be no simple one-to-one correspondence between changes in task duration and lead time. An extra week required to complete a task on the critical path will delay a project's completion by one week. An extra week required to complete a task on a noncritical path will not delay the project's completion unless there is less than a week of slack time. Thus the sequencing and parallelism or, more broadly, the inter-

15. For more on overlap in product design see Clark and Fujimoto, "Overlapping Problem Solving"'; and Mansfield and others, Research and Innovation.

16. Actually, the uncertainty about project task durations suggests that analysis using the program evaluation and review technique would be more accurate. The PERT approach is conceptually identical to the framework described here but includes expected, maximum, and minimum duration times for each task to give estimates of project duration. For a survey of the literature on PERT (which was first used to accelerate the development of the Polaris missile) see Richard S. Rosenbloom, "Notes on the Development of Network Models for Resource Allocation in R\&D Projects," IEEE Transactions on Engineering Management (June 1964), pp. 58-63. 
dependence of activities will affect the relationship between task duration and lead time.

A project can thus be thought of as a network of interrelated engineering and coordination activities of uncertain duration. The number and duration of activities will determine the total number of engineering hours the project will consume. The duration and interdependence of activities will determine lead time.

\section{PROJECT STRATEGY: COMPLEXITY AND SCOPE}

The existence of a critical path suggests that development performance will be affected by the number of unit tasks and the complexity of their interactions and by the capability of the organization to create and process information. The first set of variables we call project strategy; the second, project organization. ${ }^{17}$ The strategy of a project is defined in the first instance by the choice of market and the approach to product differentiation. These choices determine the extent of technical innovation and of technical performance improvement sought, both of which influence the complexity of engineering and coordination tasks.

The second element of project strategy is the project's scope. While the choice of market and mode of differentiation determine the engineering tasks, the scope of the project determines which tasks will be accomplished by the project group. For any unit engineering task, there are three possibilities: the task will be performed by the project group, it will be performed by another organization, or it has already been performed. In setting project strategy the engineers may choose to involve outside suppliers in engineering work; this shifts engineering hours outside the project and may affect lead time. The engineers may also choose to use parts developed for earlier models or other current models; this too eliminates engineering hours and, to the extent that such parts are on the critical path, may also reduce lead time. Of course, the use of suppliers and existing parts may create additional coordination tasks that offset changes in unit engineering time.

17. While there are significant differences in scope, nomenclature, and industryspecific variables, this work is similar in spirit to Mansfield and others, Research and Innovation, which investigated the determinants of development costs and lead times for a set of new ethical drugs. 
PROJECT ORGANIZATION: INTEGRATION, SPECIALIZATION, AND PROBLEM SOLVING

The project's strategy determines the number of unit engineering tasks and the complexity of interactions. But the length of a unit task, the extent of parallel processing, and the incidence of mistakes and iterations will be affected by the way the engineering group solves problems. At each stage of the development process the engineers are presented with objectives and alternative ways of meeting them. Although some alternatives are well defined and some choices are obvious, many objectives cannot be met with obvious alternatives. When this happens, the engineers have a problem, and the problem-solving cycle begins, generating more unit tasks.

In our framework, problem solving involves a search for alternatives and a procedure for testing them to find one that provides a solution. Cycles of problem solving occur on a small scale, such as the work of an individual engineer or a small engineering group, and on a large scale, such as the work of an entire department. There are five steps to the process: setting goals, generating alternatives, building models, testing, and selection. ${ }^{18}$ At the engineering stage of a car development project, for example, problem solving begins once product planning establishes performance specifications and styling objectives; these become the goals of product engineering (step 1). Product engineers then generate alternative drawings (step 2) and build prototypes (step 3). To gauge the extent to which the design meets objectives, engineers test the prototypes on proving grounds or in laboratories (step 4). At this point the process may cycle again-more drawings, prototypes, testing—until the best possible design, according to the test results, is chosen (step 5). ${ }^{19}$

Because each iteration generates more unit tasks, effective problem solving (fewer iterations) should reduce engineering hours and, if the activities are potentially on the critical path, lead time. The effectiveness of problem solving depends on two closely related aspects of organization. The first is the overall structure of the development organization,

18. This framework is a modified version of the approach developed by Richard M. Cyert and James G. March, A Behavioral Theory of the Firm (Prentice-Hall, 1963).

19. For a richer description of problem solving in the auto design process see Clark and Fujimoto, "Overlapping Problem Solving." 
which includes the pattern of specialization and the methods used for integration. Specialization affects the expertise of the engineers as well as the kinds of problems they see and the data they have to solve them. Different methods of integration (committees, rules, and so forth) affect the time required for coordination and the quality of information that flows across lines of specialization.

The second organizational element is the way in which problemsolving cycles in adjacent engineering tasks are linked. The timing of the tasks and the pattern of communication between them may affect performance. For example, an open, reciprocal flow of information in combination with parallel processing of tasks may reduce lead time. Engineering hours may also be affected if the communication system eliminates mistakes and additional work. However, executing activities in parallel in the face of significant uncertainty may lead to dead ends and mistakes even if communication is excellent. This suggests that both project strategy and project organization (and the fit between them) may have an important influence on project performance.

\section{Research Design and Basic Data}

Any study of the development process faces several problems in acquiring data. Publicly available information on R\&D either is not project-specific or does not provide evidence on the outcomes of the development process or the operating characteristics of the firm. A study of this kind thus requires collection of data in the field. Given our desire to link product development and international competition, we faced the additional requirement that the data cover worldwide competitors in an industry where product development seemed important. To meet these requirements, we focused the study on the major competitors in the world auto industry. The industry is large and important in Japan, Europe, and the United States; competition occurs on a global scale. Product development is important in that competition, and we had developed relationships and expertise in the industry through previous research.

The unit of analysis in the study was a major car development project: development of an entirely new model or a major model change in which over half the parts were newly designed. Three U.S., eight Japanese, 
and nine European auto companies participated in the research. From these companies we collected data on twenty-nine projects: six in the United States, twelve in Japan, and eleven in Europe. ${ }^{20}$ The models developed included sedans, micro-mini cars, and small vans. Model introduction dates ranged from 1980 to 1987, with suggested retail prices from $\$ 4,300$ to more than $\$ 40,000$. $^{21}$

We developed three kinds of evidence: quantitative data on the characteristics of the project (its scope and complexity) and its performance; documentary materials on the development process, including internal reports, organization charts, memoranda, and published articles; and the experience of key participants in the project. In addition to the documentary evidence, the experience of participants was our primary source on the internal operation of the project.

We relied on interviews and questionnaires to collect the data. We distributed questionnaires to key project members in each development project. To make the questions as relevant and sensible as possible, we tested pilot surveys at selected companies. The questionnaires focused on project characteristics and performance but also included questions about the development process-its organization, the role of project managers, and modes of problem solving.

We followed the questionnaires with interviews of key participants, including project managers, heads of R\&D groups, engineering administration staff, and other product and process engineers. In the interviews we asked not only about the project but about R\&D within the company as a whole. We conducted both unstructured and structured interviews,

20. Geographic references refer to the region in which the product was developed, not the home country of the parent company. Products developed by Opel, for example, are classed as European though Opel is owned by General Motors.

21. To gain cooperation, we allowed firms to select the project to be studied. There was a clear tendency to select a project which, in the firm's opinion, was successful. As a result, these projects may most accurately be thought of as best practice by each company. Because the unit of analysis was the completed project, the data did not reflect the performance of the firm's development activity as a whole. A firm's overall development performance may be affected by economies of scope, and some projects may be stopped before completion. One must be careful in extrapolating the results reported here to the whole firm. However, scope and premature termination of projects were unlikely to bias inferences about individual projects in this sample. There was little relationship between size of firm, for example (total sales, number of models), and project performance. Further, in the auto industry, major development projects tend to be completed once they are launched. Those that are killed tend to be killed very early in the planning process; dropping a project after it has been approved and engineering work has begun is rare. 
the former for getting a feel for the process and generating hypotheses, the latter for confirming hypotheses qualitatively on a comparative basis. A format was prepared for structured interviews to acquire qualitative yet comparative information among projects.

In collecting the data and in conducting analyses we used the quantitative information, documentary evidence, and interviews interactively. When anomalies or inconsistencies turned up in one source, we turned to other sources to shed light on the problem. We consistently played back to the participants the information received to ensure accuracy and understanding. This interaction involved not only raw data but the concepts behind our questions. Interaction turned out to be our most important method of checking construct validity; on numerous occasions participants suggested alternative questions that provided much better information.

\section{BASIC DATA}

This paper focuses on explaining differences among projects in lead time and total hours expended by engineers in product engineering. ${ }^{22}$ We attempted to control for differences in quality and manufacturability, but analysis of the determinants of those dimensions is outside the scope of the paper. ${ }^{23}$ Table 1 presents summary data on lead time and engineering hours, along with information on project strategy, including variables measuring the complexity of the product and the scope of the project. The table indicates that Japanese projects were completed in two-thirds the time and with one-third the engineering hours of the nonJapanese projects. In absolute terms, the Japanese used an average of 2 million fewer engineering hours and typically completed a project more

22. The focus on product engineering was dictated by the data: all firms in the sample had data on product engineering, but very few were organized to track process engineering hours. This was true in all countries in the sample. Our discussions with engineering managers about this issue, however, suggested that product and process engineering hours were positively correlated. Thus we expect that the data on product engineering hours provide an indication of what the overall productivity analysis would show, but that assumption needs to be tested in further work.

23. Work is under way in the project to collect data on product quality and manufacturability. As noted later, our preliminary analysis suggested that, at least as far as crosscountry comparisons are concerned, the absence of good data may actually have led us to understate the Japanese advantage. We shall examine this issue in further work. 
Table 1. Selected Data on Automotive Projects, by Region

\begin{tabular}{|c|c|c|c|c|}
\hline Variable $^{\mathrm{a}}$ & Total & Japan & $\begin{array}{l}\text { United } \\
\text { States }\end{array}$ & Europe \\
\hline Number of projects & 29 & 12 & 6 & 11 \\
\hline Year of introduction & $1980-87$ & $1981-85$ & $1984-87$ & $1980-87$ \\
\hline \multicolumn{5}{|l|}{ Engineering hours (thousands) } \\
\hline Average & 2,577 & 1,155 & 3,478 & 3,636 \\
\hline Minimum & 426 & 426 & 1,041 & 700 \\
\hline Maximum & 7,000 & 2,000 & 7,000 & 6,545 \\
\hline \multicolumn{5}{|l|}{ Lead time (months) } \\
\hline Average & 54.2 & 42.6 & 61.9 & 62.6 \\
\hline Minimum & 35.0 & 35.0 & 50.2 & 46.0 \\
\hline Maximum & 97.0 & 51.0 & 77.0 & 97.0 \\
\hline Average price (1987 dollars) & 13,591 & 9,238 & 13,193 & 19,720 \\
\hline \multicolumn{5}{|l|}{ Body size (percent of projects) } \\
\hline Micro-mini & 10 & 25 & 0 & 0 \\
\hline Small & 56 & 67 & 17 & 64 \\
\hline Medium to large & 34 & 8 & 83 & 36 \\
\hline Average number of body types & 2.1 & 2.3 & 1.7 & 2.2 \\
\hline \multicolumn{5}{|l|}{ Project scope indicators (average) } \\
\hline $\begin{array}{l}\text { Ratio of common parts } \\
\text { (percent) }\end{array}$ & 19 & 12 & 29 & 21 \\
\hline $\begin{array}{l}\text { Ratio of carryover parts } \\
\text { (percent) }\end{array}$ & 10 & 7 & 9 & 14 \\
\hline $\begin{array}{l}\text { Ratio of unique parts } \\
\text { (percent) }\end{array}$ & 74 & 82 & 62 & 71 \\
\hline $\begin{array}{l}\text { Share in parts procurement costs } \\
\text { (percent) }\end{array}$ & & & & \\
\hline Supplier proprietary parts & 7 & 8 & 3 & 7 \\
\hline Black box parts & 44 & 62 & 16 & 39 \\
\hline Detail-controlled parts & 49 & 30 & 81 & 54 \\
\hline
\end{tabular}

Source: Authors' survey calculations.

a. Definitions of variables: Year of introduction: calendar year when the first version of the model was introduced to the market. Engineering hours: hours spent directly on the project in question by the engineers, technicians, and other employees at the company. Suppliers' engineering hours are excluded, except when total vehicle-development works are subcontracted out under some consignment arrangement. Engineering hours of overhead are excluded. Concept generation, product planning, and product engineering are included; process engineering is excluded. Figures include neither engine nor transmission development except modification works for matching them with the total vehicle. Lead time: time elapsed from start of the development project to market introduction. Start of the project means start of organizational activities for product concept generation. Price: average suggested retail price of major versions in each model. U.S. 1987 retail prices are used wherever possible. Prices of models not sold in the United States are estimated by applying the relative price of some global models to the global models' U.S. price. Body size: micro-mini models typically have 0.55 liter engines and are sold mostly in Japan. Medium-to-large models typically have a wheelbase of 105 inches or more. Small models, often called compact and subcompact, are in between. Other than the above criteria, industry practices of size segmentations are also applied. Number of body types: number of body types significantly different from each other in number of doors, side silhouette, and so on. Common parts ratio: fraction of parts in common with other existing models at the company, based on number of parts drawings. Carryover parts ratio: fraction of parts carried over from previous mudel, in terms of number of parts drawings. Unique parts ratio: fraction of parts developed for the model in question. Measures as one minus common parts ratio minus carryover parts ratio, with double counting between the two taken into account. Supplier proprietary parts: parts developed entirely by parts suppliers as their standard products. Black box parts: parts whose basic engineering is done by automakers, while detailed engineering is done by parts suppliers. Detailcontrolled parts: parts developed enirely by car makers from basic to detailed engineering. 
than a year and a half earlier. ${ }^{24}$ These differences have significant implications in an industry in which engineers may be a constrained resource, a model's life may be only four to five years, and market demands are continually changing. ${ }^{25}$

The data in table 1 suggest that part of the apparent Japanese advantage may be due to differences in the type of vehicles being designed. The price and size distribution data indicate Japanese cars were less complex on average than European or U.S. vehicles. The Japanese projects studied include three micro-mini cars, which brought the average price down significantly. But price is not simply a surrogate for vehicle size; it may also reflect the level of luxury, performance, and quality. This seems to be at work in the U.S.-European differences. The U.S. vehicles were predominantly medium to large size, while the European vehicles were predominantly small; yet the average European price was almost 50 percent higher.

In addition to differences in the complexity of the products, table 1 shows significant differences in the role of suppliers. The Japanese make extensive use of proprietary and black box parts, particularly when compared with their U.S. competitors. The Europeans make some use of black box parts, but the U.S. mode of development relies heavily on detailed control of parts engineering. This implies that the Japanese draw more engineering resources from parts suppliers.

One might infer from table 1 that the Japanese performance advantage was overstated because the Japanese projects were, on average, less complex and narrower in scope. However, the data also show that the unique parts ratio was higher in the average Japanese project. U.S. projects used approximately twice the number of common and carryover parts, and the average Japanese project developed more body types. Thus while the evidence suggested that correcting for differences in project strategy would reduce the Japanese advantage, the magnitude of the adjustment was not clear. It is to that issue that we now turn.

24. The micro-mini cars are unique to Japan. Dropping them from the sample adds less than 200,000 engineering hours and only one month to the mean values for the Japanese projects.

25. For evidence on market demands and more detailed discussion of recent industry dynamics, see William J. Abernathy, Kim B. Clark, and Alan M. Kantrow, Industrial Renaissance: Producing a Competitive Future for America (Basic Books, 1983); and Winston and associates, Blind Intersection. 


\section{Strategy and Performance}

The two dimensions of project strategy, scope and complexity, affect the number of unit tasks in a project and the nature of their interactions. As discussed earlier, some differences in strategy (supplier participation and carryover and common parts) have a direct impact on engineering hours, while others depend on the nature of the tasks and how the organization handles them. Thus in the analysis that follows we use direct adjustment of the raw engineering hours data as well as statistical analysis to gauge the impact of project strategy.

\section{ENGINEERING HOURS, SCOPE, AND COMPLEXITY}

The first step in our analysis of engineering hours was to adjust reported hours for differences in the scope of the project. Because parts suppliers do some engineering and because some projects use parts developed in other projects, the engineering hours reported in table 1 do not measure the total engineering hours required to develop a vehicle. Of course, if all projects used suppliers and nonunique parts in the same way, the adjustment would be unnecessary. But the Americans, Japanese, and Europeans are all different.

Our approach to adjusting engineering hours is described in the Appendix. In essence we used information on the role of suppliers and the use of carryover and common parts to estimate the fraction of total engineering hours that were expended in-house by the project team. We then used that ratio to scale up the reported hours. For example, if that ratio was 50 percent (the project team accounting for half of the total engineering hours), we doubled reported engineering hours to get an adjusted figure. The adjusted data in table 2 show how many engineering hours would have been required to develop the entire vehicle in-house with no carryover or common parts. ${ }^{26}$

It is clear from table 2 that adjusting for differences in project scope

26. We use the adjusted data because it is conceptually the dependent variable of most relevance and interest. We have run the engineering hour regressions shown throughout this paper with unadjusted hours as the dependent variable and $N H$ (the "new in-house" ratio) as the independent variable (as in the lead time regressions). The qualitative findings are unchanged. 
Table 2. Engineering Hours Adjusted for Project Scope

\begin{tabular}{lcccc}
\hline & $\begin{array}{c}\text { Average } \\
\text { engineering } \\
\text { hours } \\
\text { (thousands) }\end{array}$ & $\begin{array}{c}\text { Average } \\
\text { adjusted } \\
\text { engineering } \\
\text { hours } \\
\text { (thousands) }\end{array}$ & $\begin{array}{c}\text { Nonunique } \\
\text { parts } \\
\text { percentage } \\
\text { of adjusted } \\
\text { hours }\end{array}$ & $\begin{array}{c}\text { Supplier } \\
\text { design } \\
\text { percentage } \\
\text { of adjusted } \\
\text { hours }\end{array}$ \\
\hline Total & 2,577 & 4,567 & 26 & 38 \\
Japan & 1,155 & 2,701 & 18 & 52 \\
United States & 3,478 & 4,892 & 38 & 15 \\
Europe & 3,636 & 6,426 & 29 & 35 \\
\hline
\end{tabular}

Source: See Appendix for definitions and computation of adjustment. Adjusted figures are uniformly greater because they reflect the total hours that would have been required if no supplier design work had been performed and all vehicle parts were unique.

changed the pattern of hours. The greater dependence on suppliers in the Japanese projects indicated by the supplier design percentage resulted in a significant increase in engineering hours after adjustment. The U.S. and European hours also increased, but the relative Japanese advantage narrowed substantially; the U.S.-Japan ratio went from 3:1 in the unadjusted data to 1.8:1 after adjustment; the Europe-Japan ratio fell from 3.1:1 to 2.4:1. As the ratios imply, the adjustment also created a gap between U.S. and European engineering hours. The greater supplier dependence in the European projects resulted in an average increase of 77 percent, while the comparable U.S. average was 41 percent.

While the Japanese advantage had narrowed in percentage terms, there remained a significant difference in performance to be explained. On an absolute basis the U.S.-Japan difference fell only slightly, while the Europe-Japan difference increased from roughly 2.5 million hours to 3.7 million hours after adjustment. Some part of the difference may have been due to differences in the products developed. The projects studied ranged from very small (engine less than 1 liter), relatively simple, four-passenger micro-mini cars to large, complex, high-performance luxury sedans. Such programs are likely to differ in the number of parts and systems that must be designed, the amount of testing required, and the number of alternatives examined. Other things being equal, one would expect more complex projects to require more engineering hours.

We used three variables to control for project content: size class of the vehicle, number of body types developed, and price. Studies of the 
parts structure in different sizes of automobiles have shown that small cars typically have many fewer parts. This reflects the requirements of cost and the prevalence of automation in the manufacture of small cars produced in high volume. But it also reflects a lower level of absolute performance in ride, handling, and power.

While vehicle size may capture broad differences in complexity, even within a size class there are likely to be substantial differences in engineering content. The number of body types is one source. One project may develop four or five different bodies (two-door, four-door, hatchback, station wagon), while another in the same size class may do only one. The impact on engineering hours depends on the design of the base vehicle, but a common rule of thumb in the industry is that each additional body type adds 10 to 20 percent to the hours necessary to design the base vehicle. Going from one to four body types may add as much as 50 percent.

In addition to auto size and body types, engineering hours depend on the performance level that the parts and the systems in the vehicle are designed to achieve. The development of a high-performance product involves more attention to detail and nuance, higher precision in specifying tolerances, more rigorous testing, and possibly the development of design concepts that advance the state of the art. These activities not only require people and hours but, if successful, also deliver a higher level of quality to the market and thus command a higher price. Although the price of a vehicle is affected by things other than engineering content, consumers expect it to provide some additional indication of differences in the complexity of the design and product quality. We thus expected that the larger the vehicle was, the more body types it had, and the more expensive it was, the more engineering hours it required.

Table 3 presents regressions of adjusted engineering hours on dummies for vehicle size, the number of body types, vehicle price, and region. ${ }^{27}$ Column 1 gives the simple mean difference between Japanese projects and the rest of the sample. Columns 2, 3, and 4 introduce the measures of complexity in various combinations.

27. As noted in table 1, our price values were U.S. market prices or estimates of those prices if the vehicle was not sold in the United States. To test for problems due to a U.S. pricing bias, we also collected data on each vehicle's home market price. Using these prices (expressed in 1987 dollars) in the regressions did not change the qualitative results; changes in coefficients were small and significance levels were unaffected. 
Table 3. Effects of Product Variables on Adjusted Engineering Hours ${ }^{a}$

\begin{tabular}{lcccc}
\hline & \multicolumn{4}{c}{ Engineering hours } \\
\cline { 2 - 5 } Independent variable & 1 & 2 & 3 & 4 \\
\hline Constant & 5885 & 4920 & 955 & 2661 \\
& $(612)$ & $(606)$ & $(1474)$ & $(1358)$ \\
Body size $\quad$ & & & \\
$\quad$ Micro-mini & $\ldots$ & -3564 & -2262 & -1055 \\
& & $(1526)$ & $(1428)$ & $(1269)$ \\
\multicolumn{1}{l}{ Large auto } & $\ldots$ & 47.7 & $\ldots$ & $\ldots$ \\
Body types & $\ldots$ & $(977.6)$ & & \\
& & $\ldots$ & 1086 & 1038 \\
Price & $\ldots$ & $\ldots$ & 0.109 & $(355)$ \\
& & & $(0.050)$ & $(0.062$ \\
Japan & 3184 & $\ldots$ & $\ldots$ & -2608 \\
& $(782)$ & & & $(800)$ \\
Summary statistics & & & & \\
$\bar{R}^{2}$ & .429 & .154 & .334 & .536 \\
Standard error & 2029 & 2425 & 2152 & 1836 \\
Degrees of freedom & 27 & 26 & 25 & 24 \\
\hline
\end{tabular}

Source: Authors' calculations. See text description.

a. Standard errors in parentheses. In this paper we have reported on the results of regressions in which the variables have been entered linearly. We have explored multiplicative forms and found little significant difference in our results and no differences in our conclusions. There are arguments for both forms but little theoretical basis for selecting one instead of the other.

The controls for project complexity all had the expected sign, though the magnitude and the precision of the effects were mixed. With respect to vehicle size (column 2), there are clear differences in engineering content between micro-mini cars and others, but little estimated difference between large cars and subcompacts or compacts. ${ }^{28}$ In column 3 we added body type and price and found a positive effect: more body types and a higher price were associated with more engineering hours. The estimates for body type accorded with rules of thumb we discovered in our interviews. At the mean level of engineering hours (4.6 million), reducing the number of body types from two to one would decrease engineering hours by 23.6 percent. To get a similar effect using the price coefficient, the price would have to drop from its mean value of $\$ 14,000$

28. In effect, we picked up a micro-mini car influence rather than a size influence. For this reason the dummy variable was preferable to a continuous variable, such as a measure of car length. In the remaining engineering hour regressions, only the micro-mini car size dummy was included as a size variable. 
to $\$ 4,100$, which is about the price of a micro-mini car. This implies that one-third of the difference in hours between micro-minis and the average vehicle may be explained by content differences associated with vehicle price.

Once we took into account the differences in size, body type, and price, the Japanese advantage seen in column 1 dropped by almost 0.6 million hours, or about 19 percent (column 4). Adding the Japan dummy also reduced the size and significance of the price coefficient, although the effect of body type was little changed. Thus, while the character of a project accounted for some of the raw difference in adjusted engineering hours between the Japanese and other producers, a significant gap remained. The point estimate in column 4 ( 2.6 million hours) suggested that Americans and Europeans used about twice as many engineering hours to complete a project in the same size class with the same number of body types and selling for the same price as did the Japanese. Those 2.6 million hours were the equivalent of one additional average car program in Japan.

\section{LEAD TIME, SCOPE, AND COMPLEXITY}

Differences in project strategy will, by definition, create differences in tasks. While the effect of those differences will depend on how the tasks are related to the critical path, we expected that adding tasks would increase lead time..$^{29}$ Thus our measures of scope and complexity should have had a positive effect on lead time. The magnitude and significance of the effect would depend on the possibilities for parallel processing, changes in coordination requirements, and the relative efficiency of suppliers. ${ }^{30}$

Table 4 shows the impact of project strategy on lead time. The mean difference between Japan and the other regions (a time advantage of

29. See Rosenbloom, "Notes on the Development of Network Models."

30. The critical path model discussed earlier suggests that changes in tasks affect lead time only if the tasks are on critical or near-critical paths. If tasks can be processed in parallel, they are less likely to appear on the critical path. Adding more parts in need of engineering (increased unique parts ratio or reduced supplier percentage or both) to the project may influence the critical path if the tasks will take longer in-house as opposed to the length of time they would take suppliers or the need for coordination activities changes. Because of these factors, the full effect of changes in project scope on lead time is uncertain a priori. 
Table 4. Combined Effects of Unique Parts and Supplier-Engineered Parts on Lead Time ${ }^{a}$

\begin{tabular}{lcccccc}
\hline & \multicolumn{5}{c}{ Lead time } \\
\cline { 2 - 7 } Independent variable & \multicolumn{1}{c}{ I } & 2 & 3 & 4 & 5 & 6 \\
\hline Constant & 62.5 & 51.5 & 45.6 & 20.2 & 35.8 & 39.5 \\
& $(2.5)$ & $(3.1)$ & $(8.3)$ & $(11.0)$ & $(11.1)$ & $(7.0)$ \\
Body size & & & & & & \\
$\quad$ Micro-mini & $\ldots$ & -11.8 & -8.1 & -4.5 & -0.3 & $\ldots$ \\
\multicolumn{1}{l}{ Large auto } & $\ldots$ & $(7.8)$ & $(8.0)$ & $(7.0)$ & $(6.3)$ & \\
& & $(5.0)$ & 5.7 & 3.9 & 0.3 & $\ldots$ \\
Body types & $\ldots$ & $\ldots$ & -0.2 & $(5.0)$ & $(4.5)$ & \\
& & & $(2.3)$ & $(2.1)$ & $(1.9)$ & $\ldots$ \\
Price & $\ldots$ & $\ldots$ & $0.57 \times 10^{-3}$ & $0.80 \times 10^{-3}$ & $0.60 \times 10^{-3}$ & $0.6 \times 10^{-3}$ \\
& & & $\left(0.3 \times 10^{-3}\right)$ & $\left(0.28 \times 10^{-3}\right)$ & $\left(0.25 \times 10^{-3}\right)$ & $\left(0.2 \times 10^{-3}\right)$ \\
Project scope $(N H)$ & $\ldots$ & $\ldots$ & $\ldots$ & 41.1 & 29.8 & 27.7 \\
& & & & $(13.6)$ & $(12.5)$ & $(11.0)$ \\
Japan & 19.9 & $\ldots$ & $\ldots$ & $\ldots$ & -12.5 & -13.0 \\
& $(3.8)$ & & & & $(4.4)$ & $(3.8)$ \\
Summary statistics & & & & & & \\
$R^{2}$ & .501 & .248 & .301 & .480 & .603 & .645 \\
Standard error & 10.1 & 12.5 & 12.0 & 10.4 & 9.1 & 8.6 \\
Degrees of freedom & 27 & 26 & 24 & 23 & 22 & 25 \\
\hline
\end{tabular}

Source: Authors' calculations. See text description.

a. Standard errors in parentheses.

twenty months) is displayed in column 1 . There was no direct adjustment of lead time data. Unlike engineering hours, where some portion of total hours was not counted, lead time reflected the total elapsed time from product concept to market. No adjustment was necessary. This meant that in addition to the measures of product complexity explored earlier (size, body types, and price), we also needed to include a measure of product scope as an independent variable. We therefore estimated the fraction of total parts developed new and developed in-house. $U$ represented the unique parts ratio (the fraction of total parts unique to this project), and $S$ the supplier ratio (the fraction of parts engineered by suppliers). Then $N H=U(1-S)$, where $N H$ is scope and varies between 0 and 1 .

The evidence on the effect of product complexity on lead time in table 4 was mixed. We found no effect for body types, suggesting that the additional activities associated with multiple body types were handled in parallel. There were significant differences among size classes, with differences between micro-minis and large vehicles amounting to almost two years. However, the extent and significance of that gap 
diminished sharply when we introduced the price variable in column 3. The coefficient on price implied that a standard deviation increase in the price $(\$ 9,500)$ added 5.4 months to lead time.

The evidence in column 4 shows that scope $(\mathrm{NH})$ had a strong positive effect on lead time. Thus for a given level of complexity, bringing more of the work in-house and using fewer common parts increased lead time. The coefficient on $\mathrm{NH}$ in column 4 implied that bringing an additional 20 percent of the engineering effort in-house and inside the project (for example, an increase of $\mathrm{NH}$ from 0.4 to 0.6 ) would add eight months to lead time.

Taking into account the parts engineering structure and the project's complexity reduced the estimated Japanese advantage in lead time from 19.9 to 12.5 months. Adding the Japan dummy also reduced the coefficient on $\mathrm{NH}$. The implication was that at least some part of the Japanese lead time advantage had to do with differences in the role of suppliers and the unique parts ratio.

To sharpen understanding of the relative importance of the two factors, we examined them separately in table 5 . The results suggested that the reduction in the Japanese advantage came from controlling the supplier participation ratio, while the unique parts ratio had little effect. However, the unique parts ratio accounted for the power of $\mathrm{NH}$ to explain variation in lead time within regions. Differences in supplier participation appeared to depend on differences between the Japanese and the other producers; the variable explained little of the variation within regions.

These results underscored the advantage the Japanese firms appeared to derive from the capability of their supply base, which has been reported by a number of authors. ${ }^{31}$ The Japanese firms appeared to draw on a set of suppliers whose capability created an advantage in both engineering hours and lead time. Together with differences in product complexity, the very different supplier structure in Japan seemed to account for an important part of the Japanese advantage. We estimated that about 30 to 40 percent of the Japanese advantage in the raw data reflected differences in project strategy.

31. The importance of the supplier network in Japan has been emphasized, for instance, by Ken-ichi Imai, Ikujiro Nonaka, and Hirotaka Takeuchi, "Managing the New Product Development Process: How Japanese Companies Learn and Unlearn," in Clark and others, The Uneasy Alliance, pp. 337-75. 
Table 5. Separate Effects of Unique Parts and Supplier-Engineered Parts on Lead Time ${ }^{a}$

\begin{tabular}{lccc}
\hline & \multicolumn{3}{c}{ Lead time } \\
\cline { 2 - 4 } \multicolumn{1}{c}{ Independent variable } & 1 & 2 & 3 \\
\hline Constant & 39.5 & 49.6 & 35.1 \\
& $(7.0)$ & $(10.8)$ & $(7.9)$ \\
Price & $0.6 \times 10^{-3}$ & $0.5 \times 10^{-3}$ & $0.5 \times 10^{-3}$ \\
& $\left(0.2 \times 10^{-3}\right)$ & $\left(0.2 \times 10^{-3}\right)$ & $\left(0.2 \times 10^{-3}\right)$ \\
Project scope $(N H)$ & 27.2 & $\ldots$ & $\ldots$ \\
Inverse supplier ratio $(1-S)$ & $(11.0)$ & & $\ldots .1$ \\
Unique parts & $\ldots$ & $(12.8)$ & $\ldots$ \\
Japan & $\ldots$ & $\ldots$. & 27.5 \\
& & & $(10.0)$ \\
Summary statistics & -13.0 & -14.5 & -19.8 \\
$\bar{R}^{2}$ & $(3.8)$ & $(5.3)$ & $(3.7)$ \\
Standard error & & & \\
Degrees of freedom & .645 & .558 & .659 \\
\hline
\end{tabular}

Source: Authors' calculations. See text description.

a. Standard errors in parentheses. This is one of the few cases in which mathematical form (multiplicative/nonlinear versus linear) makes a significant difference in results. If $U$ and $(1-S)$ are both entered additively, the Japan dummy coefficient is estimated at -17.1 (standard error 4.7), whereas in the multiplicative $U(1-S)$ form reported in column 1, the Japan dummy coefficient is estimated at -13.0 (standard error 3.8).

\section{Project Organization and Performance}

Even after controlling for project strategy, Japanese firms seemed to enjoy a significant advantage in both lead time and engineering hours. The framework described earlier suggested that project performance was influenced not only by scope and complexity but also by the way the work in the project was organized and the way problems were diagnosed and solved. In this section we examine the effects of differences in organizational structure and the problem-solving process on project performance.

The literature on organization theory and R\&D suggests that developing a complex product such as an automobile confronts a firm with two organizational requirements. The first is the need to specialize engineering tasks so that many activities can be done in parallel, shortening the critical path. ${ }^{32}$ Moreover, specialization permits focus

32. See, for example, Paul R. Lawrence and Jay W. Lorsch, Organization and Environment: Managing Differentiation and Integration (Homewood, Ill.: Irwin, 1967); and Henry Mintzberg, The Structuring of Organizations: A Synthesis of the Research (Prentice-Hall, 1979). 
and the achievement of expertise. The second requirement is the need to integrate specialized activities to create a coherent whole. This means more than just fitting pieces together: integration requires that the pieces themselves be designed with system requirements in mind. Specialization and integration affect the number of people involved in a project and the time required for coordination and completion of activities.

Within a given structure of specialization and integration, project performance will depend on the way problems are diagnosed and solved. The information-processing framework described earlier suggests that how problem-solving tasks are linked will have an important influence on the effectiveness of that process. Two aspects of that linkage appear critical. The first is the degree of overlap in timing between upstream and downstream activities. The second is the pattern of communication between them. Overlap affects lead time directly but may also affect engineering hours, depending on the need for engineering changes caused by the downstream group's early start. This in turn will depend on the speed and quality of communication. Thus these two aspects of problem solving are closely interrelated.

\section{ORGANIZATIONAL STRUCTURE AND PERFORMANCE}

All the firms in our sample met the requirements for specialization and integration, but they met them in different ways. Much of the specialization we observed was determined by the technology, and in broad terms was uniform across the industry. All the firms, for example, had functional departments that handled body engineering, chassis engineering, vehicle testing, and so forth. Within these broad categories, however, the extent of specialization varied significantly. Where car doors might be the responsibility of a door systems engineer in one company, another company might have divided that work into several activities, creating in the process the door lock engineer (an actual position in at least one firm studied). We also found different approaches to integration.

Our first task was to define variables that captured the important differences in organizational structure. Much of the literature has studied integration in terms of coordination within the project group..$^{33} \mathrm{We}$ found it useful to add the need for integration between the project group and

33. This focus on internal coordination is one key aspect of the influential work by Lawrence and Lorsch, Organization and Environment. 
supporting activities within the parent company and between the project group and potential customers. This need for external integration seemed particularly important in situations (as in the auto industry) in which both the product and its context were complex and changing. The need is not only for the timely flow of good information about what related specialized activities are doing so that coordination may occur, but also for continual updating of the overall product concept through interaction with engineers and the market, and diffusion of the concept into the development process throughout the life of the project.

With the need for both internal and external linkages in mind, we defined three broad approaches to integration.

-Functional structure. Development is organized into functional departments (for example, body engineering); activities are coordinated through the functional hierarchy, rules, procedures, and traditions. There is no project manager and no matrix structure.

- Lightweight project manager. Work is organized into functional departments. A project manager is in charge of coordinating activities but has little influence over the content of the project. The project manager has little influence outside the project, works through lowerlevel liaison people within the project, and has relatively low status within the organization.

- Heavyweight project manager. The project manager is not only a coordinator but a concept champion with direct responsibility for all aspects of the project. He or she has strong influence outside the development group, works directly with the engineers (creates a project team), and has high status within the organization (equivalent to head of a major functional department, for example).

To the extent that external integration is important, we expected a clear ranking, with the heavyweight structure the most effective and the functional structure the least. ${ }^{34}$

Using the evidence developed through the interviews and question-

34. The expectation is consistent with evidence in the literature on innovation that more successful projects are often associated with the existence of a "champion" who provides critical support, motivation, and direction. See James Brian Quinn, Strategies for Change (Homewood, Ill.: Irwin, 1980); Modesto A. Maidique, "Entrepreneurs, Champions, and Technological Innovation," Sloan Management Review, vol. 21 (Winter 1980), pp. 39-76; Thomas J. Peters and Robert H. Waterman, In Search of Excellence: Lessons from America's Best-Run Companies (Harper \& Row, 1982), chap. 7; and Christopher Freeman, The Economics of Industrial Innovation (MIT Press, 1982), p. 116. 
naires, we classified each project, by region, into one of these three categories. Historically, the functional structure was the dominant mode of organizing development, and five of the twelve projects in Europe (and one of five in the United States) retained that structure. Beginning in the 1960s and accelerating (especially in Japan) in the 1970s, many firms throughout the industry introduced project management. In our sample, 69 percent (nineteen of twenty-nine) of the projects used a lightweight structure; only four had heavyweight project managers. There was a hint in the international patterns that strong project management might be associated with higher performance. All Japanese projects used project managers; the United States also used project managers, but all were lightweight; European producers appeared to make more frequent use of the functional form than their counterparts elsewhere.

Using dummy variables for lightweight and heavyweight projects, table 6 shows the relationship between the organizational variables and project performance. The engineering hours equations in columns 1 through 3 show that average adjusted engineering hours differ among the organizational types. With or without controls for project strategy, we found that heavyweight projects used far fewer hours than the functional projects, with the lightweight projects in the middle. In column 2 , with the control variables added, the heavyweight effect is about two standard deviations from the lightweight effect, which is in turn about two standard deviations from the functional mean.

Although the organizational categories consisted of projects from at least two regions, the Japanese dominated the heavyweight group and were not represented in the functional category. The implication was that organizational variables may explain some part of the Japanese effect. Adding the Japan dummy in column 4 reduces the estimated organization effects, although both remain sizable. The Japan dummy itself is much lower than it was when the organizational variables were excluded $(-2600)$. There was clearly more behind the coefficient on the Japan dummy than differences in organizational structure, but those differences seemed to play an important role.

Another picture emerged when we looked at lead time. While there were clear differences in the mean values of lead time between the organizational categories, adding the Japan dummy reduced the effect sharply. With the control variables in the equation, the heavyweight group had an advantage of 9 months over the lightweight group, which 
Table 6. Effects of Organizational Structure on Engineering Hours and Lead Time ${ }^{a}$

\begin{tabular}{|c|c|c|c|c|c|c|}
\hline \multirow[b]{2}{*}{ Independent variable } & \multicolumn{3}{|c|}{ Engineering hours } & \multicolumn{3}{|c|}{ Lead time } \\
\hline & 1 & 2 & 3 & 4 & 5 & 6 \\
\hline Constant & $\begin{array}{c}6876 \\
(1039)\end{array}$ & $\begin{array}{c}2995 \\
(1371)\end{array}$ & $\begin{array}{c}3403 \\
(1344)\end{array}$ & $\begin{array}{l}66.0 \\
(5.9)\end{array}$ & $\begin{array}{c}32.4 \\
(11.4)\end{array}$ & $\begin{array}{c}40.8 \\
(11.2)\end{array}$ \\
\hline Controls $^{b}$ & inc. & exc. & exc. & inc. & exc. & exc. \\
\hline Heavyweight manager & $\begin{array}{c}-4558 \\
(1558)\end{array}$ & $\begin{array}{r}-4578 \\
(1183)\end{array}$ & $\begin{array}{r}-3387 \\
(1349)\end{array}$ & $\begin{array}{r}-20.0 \\
(8.9)\end{array}$ & $\begin{array}{r}-17.5 \\
(6.8)\end{array}$ & $\begin{array}{r}-10.5 \\
(7.0)\end{array}$ \\
\hline Lightweight manager & $\begin{array}{r}-2436 \\
(1161)\end{array}$ & $\begin{array}{r}-2014 \\
(889)\end{array}$ & $\begin{array}{r}-1484 \\
(915)\end{array}$ & $\begin{array}{r}-13.0 \\
\quad(6.6)\end{array}$ & $\begin{array}{c}-8.5 \\
(4.9)\end{array}$ & $\begin{array}{c}5.1 \\
(4.8)\end{array}$ \\
\hline Japan & $\ldots$ & $\ldots$ & $\begin{array}{r}-1441 \\
(871)\end{array}$ & $\ldots$ & $\ldots$ & $\begin{array}{r}-9.7 \\
(4.4)\end{array}$ \\
\hline \multicolumn{7}{|l|}{ Summary statistics } \\
\hline $\bar{R}^{2}$ & .224 & .564 & .595 & .149 & .575 & .638 \\
\hline Standard error & 2322 & 1746 & 1684 & 13.3 & 9.4 & 8.7 \\
\hline Degrees of freedom & 26 & 23 & 22 & 26 & 23 & 22 \\
\hline
\end{tabular}

Source: Authors' calculations. See text description.

a. Standard errors in parentheses.

b. Controls for engineering hours: price, body type, micro-mini dummy. Controls for lead time: price, body type, project scope. Inc. means controls were included; exc. means they were excluded.

in turn was 8.5 months faster than the functional projects. While these differences were significant, the standard errors on the coefficients precluded strong conclusions, except for the gap between functional and heavyweight, where the two groups were far apart. With the Japan dummy in the equation, even this difference was not significant. Compared with the estimating equation with organization effects removed, the Japan dummy in column 6 was about 3 months less (12.5 versus 9.7).

The evidence suggested that patterns of integration had a much stronger effect on engineering hours than on lead time, although the direction of the effects was similar. In both cases the results with the Japan dummy implied that organizational structure was closely related to other sources of difference between Japan and the Western producers. This accorded with information developed in our interviews, where we found that projects with a heavyweight project manager, for example, also had distinctive patterns of specialization, information processing, and problem solving. Although these patterns were not unique to the heavyweight organization, the evidence suggested that the overall paradigm, the ensemble of internal structure and process, made the difference. 


\section{SPECIALIZATION AND PERFORMANCE}

The degree of specialization in a development organization affects the level of expertise in any given task, the complexity of coordination, and the possibility of idle time and duplication of effort. For these reasons, specialization will probably influence both engineering hours and lead time. In theory, the relationship is likely to be U-shaped. If the degree of specialization is very small, more specialization will expand expertise, permit parallel processing of critical path activities, and reduce hours and lead time. This effect usually diminishes as the degree of specialization increases, since division of the work into clear-cut subtasks becomes more difficult. At this point more specialization means more idle time and task duplication, leading to increases in engineering hours. In addition, time and resources for coordination grow as specialization increases and beyond some point may add to the overall hours and increase lead time.

The number of participants in a project provides at least a rough indicator of the degree of specialization. We collected data on the number of participants for a subset of the total sample, and also explored the issue of specialization in our field work. Although these data were not sufficient for extended statistical analysis, they provided some indication of the pattern of specialization in our sample and its relationship to performance.

Table 7 presents the mean number of project engineers by region and type of organizational structure. These data suggest that the degree of specialization is lower in Japanese projects, a difference borne out in our interviews. The heavyweight organizations have fewer people,

Table 7. Project Specialization: Average Number of Engineers, by Region and Type of Organization

\begin{tabular}{lcc||lcc}
\hline Region & Engineers $^{\text {a }}$ & $\begin{array}{c}\text { Number of } \\
\text { observations }\end{array}$ & Organization & Engineers $^{\text {a }}$ & $\begin{array}{c}\text { Number of } \\
\text { observations }\end{array}$ \\
\hline Japan & 485 & 11 & Heavyweight & 333 & 3 \\
United States & 903 & 3 & Lightweight & 573 & 15 \\
Europe & 904 & 8 & Functional & 1,421 & 4 \\
\hline
\end{tabular}

Source: Authors' survey.

a. Total number of engineers and technical support personnel who were involved with the project on more than a short-term basis. 
Table 8. Specialization and Performance Correlations

\begin{tabular}{lc}
\hline \multicolumn{1}{c}{ Item } & $\begin{array}{c}\text { Correlation with } \\
\text { number of } \\
\text { engineers }^{\mathrm{a}}\end{array}$ \\
\hline Unadjusted engineering hours & $.65(.17)$ \\
Lead time $^{\text {Adjusted engineering hours residual }}{ }^{\mathrm{b}}$ & $.60(.18)$ \\
Lead-time residualc $^{\mathrm{c}}$ & $.57(.18)$ \\
\hline
\end{tabular}

Source: Authors' calculations. See text description.

a. Standard errors in parentheses.

b. Controlling for car size, number of body types, and price.

c. Controlling for car size, number of body types, price, and scope.

especially when compared with the functional groups. Once again, our field work was consistent with this observation: we found that the heavyweight project managers often led relatively small, multifunctional teams. Functional organizations drew people from many disciplines, subdivided tasks significantly, and thus tended to be large.

Our data also indicated that greater specialization was associated with less effective performance. Table 8 presents correlations between the number of participants and measures of engineering hours and lead time using a subset of the sample. Whether we controlled for project strategy or not, projects with more people took longer to complete and consumed more total engineering hours, even after at least some control for project complexity and scope.

Our use of the number of participants to measure specialization raises the possibility that we picked up a size effect. ${ }^{35}$ Although a project is not a permanent organization, and its size depends on expected duration as well as specialization, there is at least a hint in the data that the more effective projects are likely to be smaller than average, with broader assignments for participating engineers.

PROJECT STAGE OVERLAP, INFORMATION PROCESSING,

AND PERFORMANCE

Because solving problems is the central activity in product development, the way problem-solving tasks are linked should be important to

35. The size effect is consistent with the idea that an increase in the number of people involved multiplies exponentially the communication linkages, and thus coordination costs, in a program. See Frederick P. Brooks, Jr., The Mythical Man-Month: Essays on Software Engineering (Addison-Wesley, 1975). 
project performance. The linkage between a given pair of tasks is determined by the timing of the activities and the nature of information transfer and communication between them.

Suppose, for example, that a project group is faced with an upstream problem-solving cycle (product engineering) and a downstream cycle (process engineering). The two activities may be strictly sequential, or the downstream activity may begin before the upstream activity is complete. The longer the period in which both activities are operating, the greater the degree of overlap.

Edwin Mansfield and others presented the first statistical evidence concerning overlapping activities and project performance in their study of twenty-nine innovations in the chemical, machinery, and electronics industries. ${ }^{36}$ They found a statistically significant, positive relationship between the extent of overlap and the speed with which a project was carried out. The implication was that starting sooner meant finishing sooner, unless overlap increased unit task time by the length of the overlap or more. However, the managers that they interviewed felt that increasing overlap would lead to an increase in engineering hours and thus cost because downstream activities would begin before the results of the earlier stages were known. Mistakes and pursuit of poor alternatives would lead to additional work hours to correct the problem. The expected positive relationship between overlap and cost appeared to be consistent with the data in the Mansfield study.

Our research underscored the importance of overlap but suggested that its effect on lead time and cost depended on communication and information transfer among activities.

We distinguished between two general approaches: the batch model and the dialogue model. In batch communication all data are transmitted in one shot at the end of the activity. It is thus likely that an early start on downstream activities will be based on faulty assumptions concerning the upstream activity's output and that work will have to be redone. In the dialogue model the upstream group transmits preliminary information little by little, and the downstream unit sends its own information back upstream in a continual give and take. The probability of having to repeat work is reduced, and the probability that the upstream activity will produce output that can be efficiently handled by the downstream group

36. Mansfield and others, Research and Innovation, chap. 7. 
is increased. Overlap is thus less likely to lead to increased costs. Indeed, communication from downstream may even help reduce them. ${ }^{37}$

We would like to have had a measure of overlap and of communication patterns to introduce into our statistical analysis, but obtaining it posed formidable problems. For a development project that involves thousands of unit activities and hundreds of people, coming up with an average measure is very costly in time and resources. Furthermore, the definition of unit activities differs among projects. To approach the problem, we first developed a rough measure of overlap by aggregating unit activities up to a broad level where comparability was possible and data were readily available. ${ }^{38}$ We then identified a small set of unit activities we expected to be representative and studied them through interviews and documentary evidence. The design and development of dies for outer body panels, for example, was on the critical path, and patterns of overlap and communication between body engineers and die engineers were likely to show the way problem-solving cycles were linked in the project more generally.

Table 9 summarizes the evidence we developed, comparing the degree of overlapping, the intensity of information processing, and degree of mismatch between the two in each of our three regions.

In exploring overlap, we looked at two kinds of evidence. The first was the overlapping ratio, defined as the duration of the engineering task divided by total engineering lead time. While this ratio was a gross aggregation of the project schedule, it provided a rough indicator of true stage overlapping. We also looked at clinical data on the timing of resource commitment activities, specifically product engineering (upstream) and body die engineering (downstream). We looked at detailed timing charts and specified some key sequences of the activities (die design versus prototype, die cutting and prototype). We also looked at how complete the upstream activity (for example, testing) was when the downstream activity started.

The results (table 9) indicated that the Japanese projects were highly overlapped in activities, the U.S. projects less so. European projects

37. For example, rounded corners are easier to mold with precision than square corners but harder to machine. Reminding product engineers of this may ultimately reduce process engineering time.

38. This approach was consistent with the analysis performed by Mansfield and others, Research and Innovation. 
Table 9. Patterns of Overlapping and Information Processing, by Region

\begin{tabular}{|c|c|c|c|}
\hline Indicators & Japan & United States & Europe $^{\mathrm{a}}$ \\
\hline \multicolumn{4}{|l|}{ Overlapping } \\
\hline $\begin{array}{l}\text { Engineering overlap- } \\
\text { ping ratio }\end{array}$ & High (1.63) & Medium (1.53) & Low (1.37) \\
\hline $\begin{array}{l}\text { Overlapping between } \\
\text { die design and } \\
\text { prototype }\end{array}$ & $\begin{array}{l}\text { Die design starts be- } \\
\text { fore 1st prototype } \\
\text { complete }\end{array}$ & $\begin{array}{l}\text { Die design starts after } \\
\text { 1st prototype com- } \\
\text { plete }\end{array}$ & $\begin{array}{l}\text { Die design starts after } \\
\text { 1st prototype com- } \\
\text { plete }\end{array}$ \\
\hline $\begin{array}{l}\text { Overlapping between } \\
\text { die cutting and } \\
\text { prototype }\end{array}$ & $\begin{array}{l}\text { Die cutting starts be- } \\
\text { fore last prototype } \\
\text { complete }\end{array}$ & $\begin{array}{l}\text { Die cutting starts after } \\
\text { last prototype com- } \\
\text { plete }\end{array}$ & $\begin{array}{l}\text { Die cutting starts after } \\
\text { last prototype com- } \\
\text { plete }\end{array}$ \\
\hline $\begin{array}{l}\text { Completeness of } \\
\text { prototypes when } \\
\text { testing starts }\end{array}$ & $\begin{array}{l}\text { Sufficiently representa- } \\
\text { tive but not perfect }\end{array}$ & $\begin{array}{l}\text { Often not representa- } \\
\text { tive enough }\end{array}$ & $\begin{array}{l}\text { Regarded as perfect } \\
\text { when tested }\end{array}$ \\
\hline \multicolumn{4}{|l|}{ Information processing } \\
\hline $\begin{array}{l}\text { Formal designs released } \\
\text { to body engineering }\end{array}$ & Three & Two & Two to three \\
\hline $\begin{array}{l}\text { Intra-R\&D communica- } \\
\text { tion }\end{array}$ & $\begin{array}{l}\text { Formal and informal; } \\
\text { intense through ne- } \\
\text { cessity to coordinate }\end{array}$ & $\begin{array}{l}\text { Mostly formal through } \\
\text { frequent large meet- } \\
\text { ings }\end{array}$ & $\begin{array}{l}\text { Mostly informal; in- } \\
\text { tense through engi- } \\
\text { neering tradition }\end{array}$ \\
\hline $\begin{array}{l}\text { Production-R\&D com- } \\
\text { munication }\end{array}$ & $\begin{array}{l}\text { Formal and informal; } \\
\text { intense through ne- } \\
\text { cessity to coordinate }\end{array}$ & $\begin{array}{l}\text { Mostly formal through } \\
\text { frequent large meet- } \\
\text { ings }\end{array}$ & $\begin{array}{l}\text { Mostly formal infre- } \\
\text { quent meetings }\end{array}$ \\
\hline \multicolumn{4}{|l|}{ Information mismatch } \\
\hline $\begin{array}{l}\text { Ratio of engineering } \\
\text { change costs in body } \\
\text { dies (percent) }\end{array}$ & $10-20$ & $30-50$ & $10-30$ \\
\hline $\begin{array}{l}\text { Surprises by down- } \\
\text { stream engineers }\end{array}$ & Moderate & Frequent & Infrequent \\
\hline $\begin{array}{l}\text { Delay of introduction } \\
\text { date }\end{array}$ & 1/6 delayed & $1 / 2$ delayed & $1 / 3$ delayed \\
\hline $\begin{array}{l}\text { Impact of overlapping } \\
\text { on lead time }\end{array}$ & $\begin{array}{l}\text { Significant (correlation } \\
\text { coefficient }-0.64 \text { ) }\end{array}$ & $\begin{array}{l}\text { Not significant (correlat } \\
\text { U.S. and European sa }\end{array}$ & $\begin{array}{l}\text { ion coefficient } 0.12 \text {, } \\
\text { mples combined) }\end{array}$ \\
\hline \multicolumn{4}{|l|}{ Summary } \\
\hline Overlapping & High & Middle & Low \\
\hline Information intensity & High & Low & Middle to low \\
\hline
\end{tabular}

a. Profile is for companies based in Europe; subsidiaries of U.S. automakers are roughly similar to the parent companies.

tended to be the least overlapped, that is, by far the most sequential of the three.

A number of indicators were used to assess each project's intensity of information processing. One was whether product development released semifinal design information to the die group in addition to the final release, which would indicate a dialogue. In examining the release of engineering drawings to die development groups, for example, we found that the Japanese released preliminary information more fre- 
quently; three releases was common practice. The U.S. projects typically had two formal releases, while the Europeans were usually between these figures.

Interviews and observation provided additional information on the density of information exchange. We assumed that preliminary information tended to be processed better through informal, direct contacts at working levels. We found that the Japanese communicated informally and intensively both intrafunctionally and interfunctionally (that is, more in a dialogue mode), while the U.S. patterns were much more formal. The Europeans were again in the middle, with close, informal communication inside product engineering and formal communication across the functions.

To support this observation, we also looked for clinical evidence that might indicate a process mismatch, that is, a combination of overlapping stages and batch information transfer. The assumption was that a significant amount of confusion in the development process (high cost of engineering changes, frequent surprises, delay of market introduction schedules, and so forth) could imply that the project had adopted highly overlapping and low-intensity (batch) information processing at the same time.

Our clinical data indicated significant mismatches in U.S. projects. Although they had a relatively high degree of overlap, information transfer was not intense enough to support it efficiently. The European projects had less overlap but moderately intense information processing (greater information exchange). Thus while there were fewer surprises and delays, they did not take advantage of their information structure to reduce lead time.

Finally, for relations between the overlapping ratio and lead time, we found a strong negative correlation in the Japanese data but little effect in the rest of the sample. The Japanese projects were getting greater benefits from overlapping problem-solving stages than the U.S. and European projects. This may be another, although rough, indication of fewer mismatches or more downstream-oriented designs, or both, in the Japanese projects.

To summarize the data in table 9, the Japanese projects show a high degree of overlap and intensive information transfer. U.S. projects show moderate overlap and low-intensity batch information processing-a fair amount of mismatch. European projects show the lowest degree of overlap, accompanied by a mix of batch and dialogue information 
transmission. Thus some portion of the Japanese advantage in both lead time and engineering hours may be explained by the regional differences, among the most striking we encountered in our field work. Other research into technology development differences elicited a similar pattern. ${ }^{39}$ These conclusions are tentative, but they appear worth further investigation. We believe the two-dimensional overlap-information transfer model is more useful than the simpler one-dimensional model. Still, as Mansfield and others observed when introducing overlap as an explanatory variable, "This is an interesting result, but only a beginning" (p. 152).

RELATIONSHIP BETWEEN LEAD TIME AND ENGINEERING HOURS

The statistical and clinical evidence suggests that the pattern of integration, the degree of specialization, and the nature of problem solving accounts for a significant portion of differences in project performance. These results are based on separate analyses of lead time and engineering hours. Theory suggests that, at least ex ante, there is a trade-off between lead time and engineering hours; thus their relationship deserves examination. The existence of a trade-off does not, however, explain the Japanese advantage. From the data on lead time alone, one might expect that the Japanese had achieved faster production by adding more engineering hours than their U.S. and European competitors. But that is not the case; the data show a significant advantage in each dimension, so that while trading engineering hours for lead time does not explain what the Japanese have done, the nature of the relationship between hours and lead time may nonetheless shed some light on the validity of the conclusions we have drawn about the role of the project organization.

Figure 1 shows the distribution of engineering hours and lead time in unadjusted form. As one might expect in unadjusted data, there is a strong positive relationship between the two measures; the correlation coefficient is 0.693 , with a standard error of $0.139 .{ }^{40}$ Yet this positive

39. See, for example, Imai and others, "Managing the New Product Development Process."

40. As project complexity and scope increase, the cost-time trade-off curve moves further from the origin. Figure 2 shows the results of projects across a family of curves rather than projects on a single curve. Much of the work described earlier in the section "Strategy and Performance" can be thought of as collapsing this family of curves into a single base curve to achieve project comparability. 
Figure 1. Unadjusted Engineering Hours and Unadjusted Lead Time ${ }^{a}$

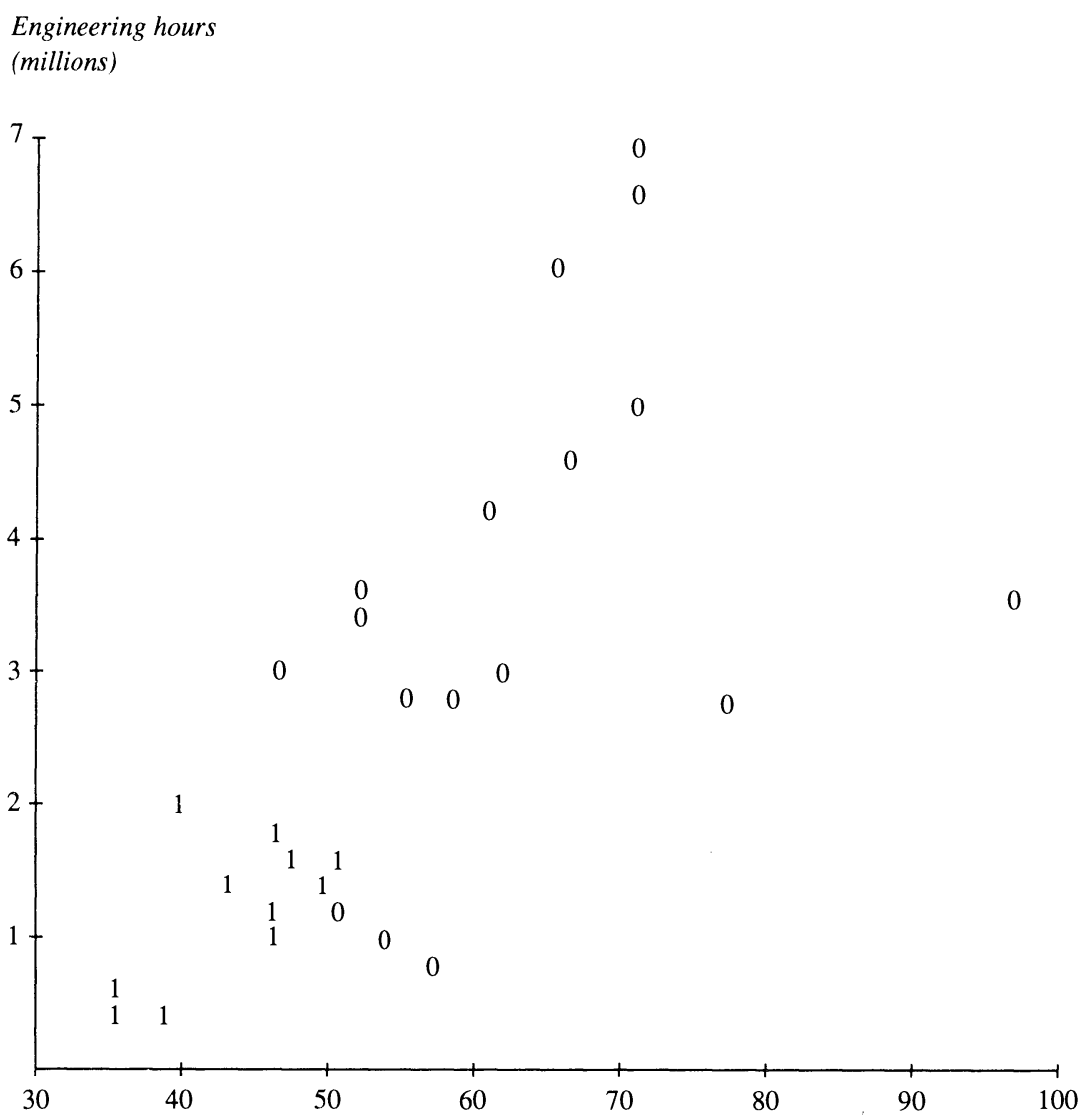

Lead time (months)

Source: Authors' calculations.

a. 0 stands for non-Japanese projects; 1 for Japanese projects

relationship appears even after controlling for project strategy and patterns of integration. Figure 2 plots residuals from the fully specified regressions reported in table 6; the Japanese projects are identified with the numeral 1 . In computing the residuals, we set the Japan dummy equal to zero for all observations so that we might see the residuals with the Japan effect present.

There are two interesting patterns in these data. First, although the Japanese projects had a significant advantage, a few projects from both 
Figure 2. Adjusted Engineering Hours and Adjusted Lead Timea

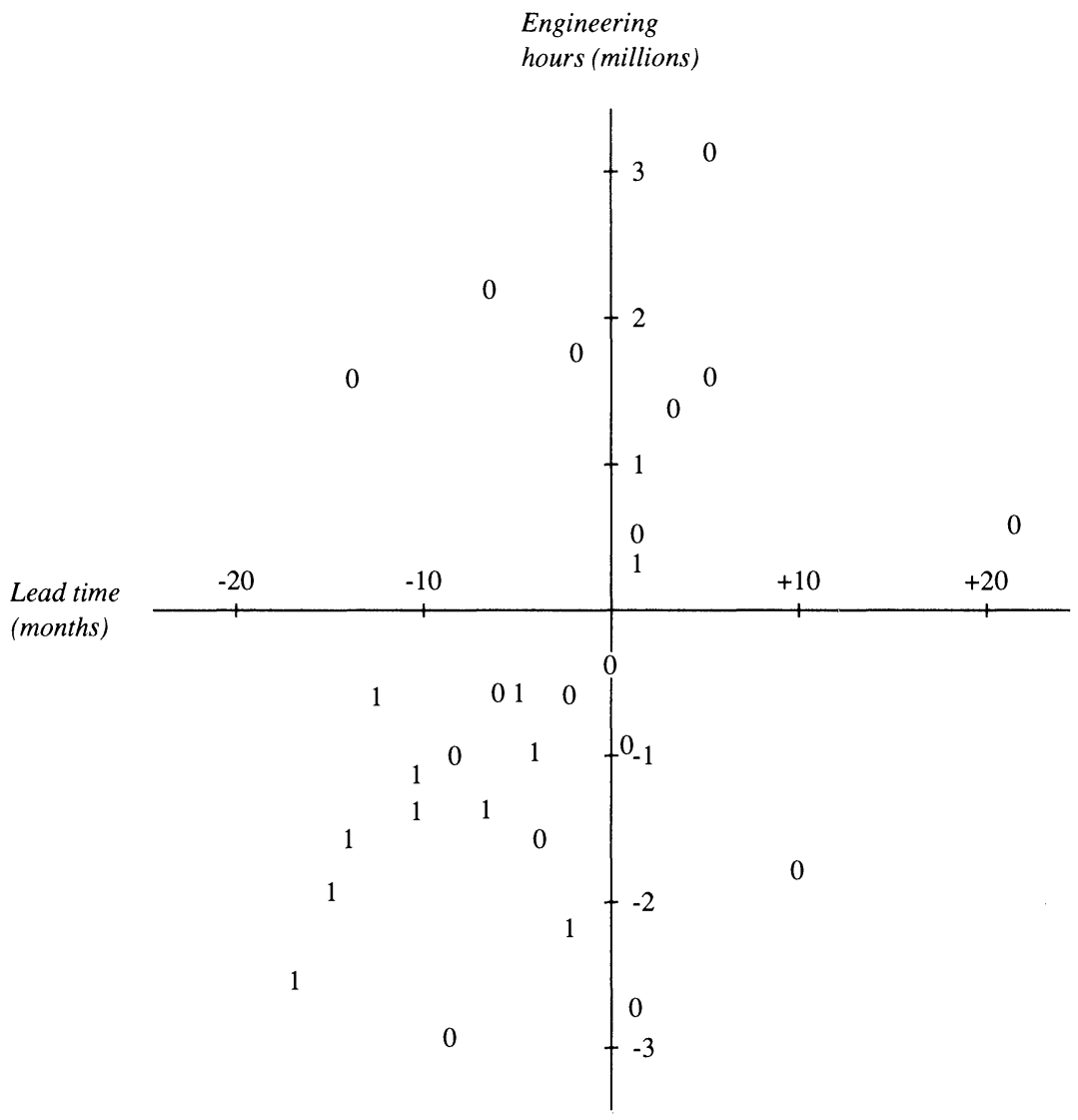

Source: Authors' calculations.

a. 0 stands for non-Japanese projects; 1 for Japanese projects.

the United States and Europe shared some characteristics with the Japanese. They were less specialized than the average U.S. and European project, used smaller development teams, and made more use of the dialogue mode of information transfer. This pattern suggested that what we saw in Japan was not uniquely Japanese but a different paradigm, elements of which could find successful application in other countries.

The second interesting pattern in figure 2 is the strong positive relationship between engineering hours and lead time in the Japanese data; the correlation coefficient is 0.753 with a standard error of 0.208 . The U.S. and European data show a random pattern of residuals, that 
is, a correlation coefficient of 0.100 with a standard error of 0.257 . While issues of estimation may explain some of the result,${ }^{41}$ our field work suggested the pattern in the Japanese data was what we would expect to occur in the kind of organization characteristic of most of the Japanese projects in our sample: multifunctional, with a dedicated team, significant overlap in timing, a high degree of integration in problem solving, and little slack in the organization. In such an organization, a random shock that causes a delay or a change in one part of the project will propagate. Because the team is dedicated and there is little slack, people in other activities will continue to work; and because activities are integrated, other parts of the project will need to keep abreast of changes in the affected activity to maintain a coordinated effort. As a result, engineering hours turn out to be higher than expected. Even those Japanese projects that did not follow this pattern exhibited so little slack that shocks may have been able to propagate.

Random shocks are likely to have very different effects in a functional organization that has little overlap, limited integration, and some slack because these characteristics buffer activities from one another. Shocks do not propagate. People not directly affected by the shock simply work on other projects. Since activities are not tightly integrated, there is little need for additional coordination time. Slack resources help absorb the shock, but overall engineering hours may not change at all.

The data in figure 2 are thus consistent with the idea that the Japanese effect remaining after project strategies are controlled reflects differences in project organization. Taken together, the evidence on integration, specialization, and problem solving shows that much of what we see in the data reflects fundamental differences in the way projects are organized and managed.

41. The positive relationship between cost and lead time was consistent with a number of estimation problems. Missing variables (for example, specialization and problem solving) that are associated with both improved costs and lead times would generate the observed relationship if they were present in increasing amounts across the projects as observations move from the origin. Alternatively, the pattern in the Japanese data is consistent with a multiplicative Japan dummy (as opposed to the additive dummy actually used) if project size increases as the observations move from the origin. Finally, this pattern would be expected if our control variables were effective only among the non-Japanese projects. An observation-by-observation analysis suggested that none of these issues was significant. We must look elsewhere to explain the positive relationship between engineering-hour and lead-time residuals. 


\section{Alternative Explanations}

There are, of course, competing hypotheses that may explain our data. Three that deserve specific comment involve use of additional capital equipment, differences in quality and manufacturability, and scale. Producing comparable output faster and with less labor might plausibly be explained by greater use of automation, perhaps especially computer-aided design (CAD) and computer-aided engineering (CAE). More intensive Japanese use of computer systems might explain part of the regional performance differences. But our interviews with project engineers as well as secondary sources suggested that CAD/CAE systems were heavily used by engineers at all the companies studied, with no evidence to indicate that the Japanese used them more intensively.

Differences in quality and manufacturability could explain the Japanese advantage if Japanese products in comparable size classes performed worse, were aesthetically inferior, or were more difficult to manufacture. But none of these is true. The evidence in the trade press, in independent product evaluations, and in the marketplace is clear: Japanese products are, if anything, of higher quality than those produced in the United States and are at least competitive with European products. The evidence on manufacturability is even stronger. Data on product reliability, defect rates, and manufacturing productivity point to Japanese leadership..$^{42}$ Our own evidence on manufacturability suggests that the Japanese projects in our sample had many fewer design bugs and went through manufacturing start-up with many fewer problems ${ }^{43}$ It would appear that we should add an advantage in manufacturability to the advantages in hours and lead time.

Finally, differences in scale could account for differences in efficiency. The scale effects considered here were those associated with firm size

42. See Abernathy, Clark, and Kantrow, Industrial Renaissance.

43. As part of our ongoing research we have investigated production start-up at twelve of the firms in our study (six Japanese, three U.S., and three European). The Japanese took an average of 1 month to go from production start to sales start; the U.S. average was 4 months, the European 2 months. The Japanese projects averaged 4 months to return to normal productivity levels and 1.4 months to return to normal quality levels, U.S. projects averaged 5 months for productivity and 11 months for quality, and European projects 12 months for both productivity and quality. 
(economies of scale) or firm-wide development activity (economies of scope). Our projects showed virtually no relationship, positive or negative, with either measure of scale, suggesting that the size of the project, considered earlier, is the relevant measure of scale for these activities.

\section{Summary and Conclusions}

We began this paper with two objectives: to document the international differences in product development performance in the auto industry and to identify their sources. One of the most striking aspects of the data we developed is the large Japanese advantage in lead time and engineering hours. A part of that advantage reflects differences in the kinds of vehicles developed and the role of suppliers. Much of it, however, is real. The best of the Japanese firms seem able to develop a vehicle of competitive quality in much less time and with many fewer engineering resources than their U.S. or European competitors.

That advantage appears to depend on the strength of the Japanese supply base and the way projects are organized and managed. While our data did not lend themselves to a detailed discussion of supplier relations, Japanese suppliers play a significantly different role in the design process than most of their U.S. and European counterparts. This role may be a major source of the Japanese advantage in lead time. The organization of the project is also important. In the best of the Japanese projects, a heavyweight project manager leads a multifunctional team, in which problem-solving cycles are overlapped and closely linked through intensive dialogue. While there are exceptions, the patterns in the United States and Europe are in general quite different, and these differences appear to be important in explaining the Japanese advantage.

How did the differences originate? Why do Japanese firms use a different engineering paradigm? Why are European producers so strongly linked to a functional organization structure? A full treatment of such questions is beyond the scope of this paper, but we can suggest a possible explanation.

Until the early 1970s, the European, Japanese, and U.S. automobile markets were not closely linked. The customers, types of products, and competitive structures were different. While there was some trade in certain market segments, companies' decisions and actions were domi- 
nated by domestic market issues. The engineering paradigms that developed thus reflected the particular circumstances in which the domestic firms competed.

In Japan, rapid growth of production and intense domestic competition conditioned the development of engineering capability. Chronic shortages of engineers placed sharp limits on specialization and a premium on supplier capability. Competition motivated a search for faster development cycles and more efficient use of engineers. ${ }^{44}$ U.S. and European competitors also created approaches to engineering and development that reflected the constraints and opportunities they faced. And those approaches were successful in those environments. But as markets have become more closely linked, the differences in engineering paradigms have begun to have significance for international competition. Both project strategy and organization have begun to change among U.S. and European competitors. Adjustment costs are high, however, and adjustment periods long. Thus fifteen years after the first oil shock, we have observed sharp differences in strategy and organization, and consequent differences in performance. ${ }^{45}$ Our expectation is that the paradigms will continue to evolve in all three regions, and that differences are likely to narrow.

Our results have implications for practice and for further research. The evidence on strategy and organization illuminates the determinants of project performance that the firms in our study have already found useful. To the extent that the study results are representative of developments in the manufacture of complex products, managers in other industries may find the results on heavyweight project managers, the role of suppliers, and the problem-solving process of interest.

Several issues deserve further research. We plan to examine in particular the role of suppliers in development, the engineering problemsolving process, and the relationship between lead time and engineering

44. See Michael A. Cusumano, The Japanese Automobile Industry: Technology and Management at Nissan and Toyota (Harvard University Press, 1985).

45. Because the Japanese were already producing smaller, fuel-efficient front-wheel drive vehicles before the oil crisis, the more fuel-efficient designs that have become common since 1973 may have represented a smaller technological step for them. But while this explanation may seem plausible when comparing Japan with the United States (though even here, the projects studied were not the first front-wheel drive, post-oil-shock vehicles the firms developed), it clearly cannot be applied to explain the major differences between Europe and Japan. 
hours. In addition, we need to examine empirically the role of product development in competition, particularly in a dynamic environment. The issues we have examined also need to be studied in other industries. It is especially important to study the development process and its role in competition in situations in which basic technologies are changing more rapidly than is true with automobiles. This kind of work will shed light on the power of the concepts we have developed, the robustness of the engineering paradigms we have uncovered, and the general role of product development in international competition.

\section{Appendix: Adjustment of Engineering Hours}

A vehicle design project's engineering hours fall into four classes:

$-E I$ : parts-specific engineering hours internal to the project. $E I$ represents the development hours spent by the project team on engineering specific parts and components.

$-E C$ : engineering-hour equivalent for nonunique parts. This class of engineering time is of the same type as $E I$, but the work is performed by an earlier project team (in the case of carryover parts) or a project team working on another vehicle currently in production (common parts).

$-E S$ : parts-specific engineering hours performed by outside suppliers. Parts suppliers may participate in the engineering of new parts. This work is conceptually similar to $E I$ and $E C$ but is, again, performed by a group different from the project team.

$-E T$ : total parts-specific engineering hours. By definition, $E T=$ $E I+E S+E C$.

$-N$ : non-parts-specific engineering hours. Designing a new vehicle requires more than just the design of a large number of parts. Such activities as concept generation, product planning, packaging, styling, prototype vehicle assembly, and vehicle testing are all examples of critical engineering tasks that are not component-specific. Engineering hours that are vehicle- but not parts-specific are represented by $N$.

The engineering hours data we wanted to analyze were the total vehicle engineering hours, $M H a d j=N+E T$. Unfortunately, firms measured only the project team's hours, which is MHobs $=N+E I$. The scope of the projects varied significantly, so we had to develop project-specific adjustment factors. What we needed was some adjust- 
ment factor, $A$, such that $M H a d j=M H o b s \times 1 / A$ or $A=M H o b s /$ MHadj $=(N+E I) /(N+E T)$.

$A$ can be interpreted as the in-project engineering ratio as it refers to the fraction of total vehicle engineering work done by the project team.

\section{COMPUTING THE ADJUSTMENT FACTOR}

Let $b$ represent the fraction of total vehicle work that is part- and component-specific: $b=E T /(N+E T)$.

We define the fraction of nonunique (common) parts engineering to total parts engineering, $C$, and the fraction of unique parts development performed by suppliers, $S$, as $C=E C / E T$ and $S=E S /(E S+E I)$. Now by substitution,

$$
\begin{aligned}
A & =(N+E I) /(N+E T)=\mathrm{b}(N+E I+E S-E S) / E T \\
& =b\{N+E T[(1-C)-E S]\} / E T=b[N+E T-C(E T-E S)] / E T \\
& =b[1 / b-C(E T+E S) / E T]=1-b[C+E S / E T] \\
& =1-b\{C+[E S /(E S+E I)](1-C)\}=1-b[(C+S)(1-C)] .
\end{aligned}
$$

This form has a very direct interpretation. It says that $A$, the in-project design ratio, is equal to one minus the fraction of the total project that is nonunique parts-specific engineering, $b C$, and the supplier-performed, unique parts-specific engineering, $b[S(1-C)]$.

What are needed now are estimates of $S, C$, and $b$. If $S$ is the ratio of supplier participation in new parts development, then $S=E S /(E S+$ $E I)=S P+(B B \cdot B B O)$, where $S P$ is the supplier proprietary parts ratio, $B B$ is the black box parts ratio, $D C$ is the detail-controlled parts ratio (so that $S P+B B+D C=1$ ), and $B B O$ is the black box outside engineering ratio.

These ratios were determined as follows. In our questionnaire we asked project engineers about the fraction of each of the following parts categories as a fraction of the total value of purchased parts:

-Supplier proprietary parts: those parts developed entirely by parts vendors as their standard products. Almost all the engineering work for developing such parts is naturally done by the suppliers. Batteries, spark plugs, and tires are examples of this category.

-Black box parts: those parts whose basic engineering (exterior, interface structure, performance specifications, and so forth) is done by 
the automakers, while detailed engineering (engineering drawings, parts prototype building, parts testing), is done by the suppliers. Radiators, air conditioners, and other functional parts may be classified here.

-Detail-controlled parts: those parts developed entirely by the automakers. Many of the body-related parts belong to this category.

The questionnaire asked the engineers to estimate the share of each category $(S P, B B$, and $D C)$ by value. They answered in terms of the fraction of total procurement costs, so that the three numbers add to 1 . Assuming that average engineering contents are similar for all parts categories, these indicators reasonably represent the share of engineering work load in each category.

We also collected data on the split of engineering hours between automakers and parts suppliers for each parts category. After discussion with engineers at several manufacturers, we estimated the suppliers' fractions as follows: supplier proprietary parts showed all engineering performed by the supplier, black box parts were 70 percent engineered by the supplier, and detail-controlled parts had no engineering provided by the supplier. Using these data, we estimated

$$
S=E S /(E S+E I)=S P+B B \cdot B B O=S P+B B \cdot 0.7 .
$$

The nonunique parts ratio, $C$, was constructed as $C=C 1+C 2$, where $C 1$ is the fraction of parts common with other existing vehicles in the firm, in terms of number of parts, and $C 2$ is the fraction of parts carried over from the predecessor model.

The respondents answered by classifying detail parts drawings (typically 2,000 to 3,000 ) as new or nonunique. Assuming that the engineering content for each part is distributed similarly in both categories, the ratio can be regarded as a reasonable indicator of engineering work load.

After these steps, the unique parts ratio was calculated as $1-C=$ $1-C 1-C 2$, and the nonunique parts ratio as $C=C 1+C 2$.

We assumed that $b$, the fraction of parts-specific hours in total hours, was a constant within each region. (We also tested the effect of holding $b$ constant across all three regions. It had little if any effect on our results.) The figures we used were Japan, 0.9; United States, 0.7; and Europe, 0.8 . These figures are based on interviews with several firms in each region. The interviews did not request estimates of $b$ directly because, as noted earlier, the firms did not monitor nonproject team hours. Instead, we asked them to estimate $E I$ as a fraction of $N+E I$, 
that is, to estimate the part of the project team's engineering work that was parts specific. The ratio $b$ could then be calculated based on the known data:

$$
\begin{aligned}
a & =E I /(N+E I) \\
N & =(1-a) \cdot M H o b s \\
E I & =a \cdot M H o b s \\
E T & =E I+E S+E C=E I(1+E S / E I) /(1-C) .
\end{aligned}
$$

THE ADJUSTMENT

From the above assumptions and figures it was possible to estimate an adjustment factor, $A$, for each project by using project-specific figures for all variables with the exception of the regional estimates of $b$. Adjustment factors were computed and, when applied to the reported engineering hours data, produced the adjusted engineering hours data reported in table 2 . 


\section{Comments and Discussion}

John Meyer: This paper is particularly rich in the quantity and quality of its data. The authors' hypotheses are plausible. However, their case is not quite proved. Three basic problems need further investigation. First, there is the matter of how the data are defined and interpreted. Second, problems of model specification arise. Finally, and closely related to model specification, there is the possibility that alternative hypotheses might explain at least some of the observed effects as well or better than the hypothesis advanced. Many of my comments will thus be concerned with questions of research strategy or approach.

Let me start with a few examples of problems in sample design and data interpretation. The price data on automobile models are very important to the authors' explanations. They specify that 1987 U.S. retail automobile prices are used "wherever possible." When these prices were unavailable, they derived estimates by applying relative price or markup ratios from global models and comparisons. This methodology makes interpretation of the resulting price data somewhat uncertain. Are the relationships between markups really that constant despite the somewhat special characteristics of the U.S. market (such as different requirements for antipollution equipment)? Casual observation strongly suggests that the manufacturers of Mercedes and some other makes charge higher markups in the U.S. market. A research strategy that would provide better controls, although costly in terms of degrees of freedom, would be to restrict the sample to models actually traded in U.S. markets so that all prices would be directly comparable.

Another data problem arises with the body size variable. In the end (although they seem to have collected more data than this usage would indicate) the authors essentially adopt a simple dichotomy between 
micro-minis, as based on three Japanese cars or cases, and all other body sizes. But other continuous-size measures-direct weight measures, litterage, engine displacement-are available and usually provide more information.

An obvious question emerges. What would happen to the regressions if the three micro-mini models were removed from the sample? The micro-minis are not only a very special subsample, but they are sold only in Japan, so their prices do not allow direct comparisons with those in the U.S. market. Results with and without this subsample should be contrasted.

Similarly, what is the relevant unit of observation, or at least of aggregation? The authors rely heavily on the nation-state as a basis for aggregation. But auto manufacturing is an international industry with some companies involved in several different countries. (I am not sure, for example, just why General Motors Europe comes under the U.S. aggregations in this paper.) I can also understand why a company aggregation, which would be in some ways a more interesting way of summarizing the data, might not be possible because of confidentiality problems. But we can at least wish and hope. And certainly we should know more about just exactly how the "national identities" of multinational companies are established.

Some very interesting data manipulation goes into the breakdown and adjustment of the key variables for engineering hours. Most of the authors' adjustments of directly observed engineering hours seem to involve an assumption, which may or may not be true, that non-partsspecific engineering hours, engineering coordination or overhead hours, are not conditioned by the mix of parts-specific hours. An alternative and better research strategy might be to avoid these potentially controversial adjustments. Rather than spend so much time analyzing the adjusted data (which usually incorporate some arbitrarily assigned unitary coefficients), perhaps it would be better to concentrate on simply explaining the directly observed engineering hours, broken down between directly observed, parts-specific internal hours and non-partsspecific hours.

All this also leads into questions of model specification. The authors use two dependent variables: engineering hours, adjusted apparently for nonunique and externally supplied parts, and lead time. A better alternative might be to employ three dependent variables, all directly observ- 
able: the parts-specific internal engineering hours, non-parts-specific engineering hours, and lead time. It would then seem at least conceptually possible-in fact the authors acknowledge this and have a separate ad hoc bivariate study at the end of the paper exploring the matter-that the proper structure is simultaneous or recursive, and thus a bit more complicated than the simple unidirectional regressions used in the paper.

For example, $N$, general engineering hours, taken as a separate dependent variable, would seem sensibly specified as a function of all the other engineering hours, whether inside or outside. In fact, it would be interesting to see what relative weights might be in terms of how many general engineering hours are needed as the parts-specific activity is divided differently between inside and outside sources.

Internal parts-specific engineering hours-of which, again, the authors have direct observations-might be hypothesized to be a function of all kinds of variables, perhaps many of them not now included in the study. For example, a target-development period might make an interesting explanatory variable. The actual lead time itself might make still another. Past company practice, as represented by lagged engineering hours of employment, might also be of interest. My guess is, too, that degree of company vertical integration might condition engineering practices and needs. Therefore, General Motors might be rather different in its engineering practices from Chrysler and Ford because of wellknown differences in supplier relationships and practices.

The omission of a model-year variable is also rather strange. The Japanese cases are concentrated in the 1980-85 period. All the U.S. cases come from 1984-87, while the European cases span the whole period. There could be some problems interpreting a model-year variable, but it would be intriguing and it might have some effect (providing needed control of some irrelevant extraneous effects, if nothing else). For example, perhaps the earlier the model year, all else equal, the less complex new models might be, with fewer attendant engineering needs.

The third dependent variable, lead time, might be a function of, and respond differently to, different categories of engineering-hour inputs, such as inside or outside parts-specific. Again, model year might have an effect. One could also hypothesize that the different lead times, projected or realized, could have some interesting interdependencies with both general engineering-hour and internal, parts-specific engineering-hour requirements. 
In short, there are many reasons for suspecting that the structural specification of these models could be improved. Certainly, some experimentation with alternatives seem justifiable.

Let me conclude with a few comments on alternative hypotheses. The authors' basic hypothesis is that the best Japanese firms can develop a vehicle of competitive quality in much less time and with fewer engineering resources than their American or European competitors. The authors reject, and justly so, two obvious alternatives. They quickly and thoroughly dispose of the possibility that differences in engineering capital equipment, particularly $\mathrm{CAD} / \mathrm{CAE}$, might explain the superior Japanese performance. They have an even easier time eliminating the hypothesis that the Japanese get by with fewer engineering hours because they have lower-quality and less manufacturable products. There is a lot of direct evidence refuting both hypotheses, as the authors note. If, by the way, they had run their regressions with the three Japanese microminis out of the sample, their results probably would have been even more conclusive and would have made rejection of these alternative quality and manufacturability hypotheses even more straightforward.

Another alternative hypothesis is, however, not so easily dismissed. The starting points from which engineering adaptations took place might be very different for the three groups of manufacturers. In the early 1970s, U.S. companies started with heavy, rear-wheel-drive fuel guzzlers that need considerable adaptation to meet the needs of the late 1980s. By contrast the Japanese started with light, fuel-efficient vehicles in the early 1970s. The standard family sedan that now seems to be emerging internationally almost surely bears more resemblance to Japanese cars of the early 1970s than to the typical American or even European cars of those years. Some of the authors' variables, such as the carryover in unique parts, might measure this. Still, there are a lot of dimensions to uniqueness and to parts and to carryover qualities that might not be captured very well in their model. A better measure of some of these effects might be the percentage of non-parts-specific engineering hours in total internal engineering hours. If manufacturers had to undertake more changes and effectuate more overall adaptation in their products, they might have needed more coordinating and overhead engineering hours. It is thus at least highly suggestive that these hours apparently constitute a much higher percentage for American than for European or Japanese manufacturers. 
In sum, this paper makes a strong case-plausible, intriguing, intuitively appealing. But that case is not yet fully proved. Better model and data specifications would be helpful steps in facilitating further progress.

F. M. Scherer: This paper yields fascinating results and comes from a research effort of impressive scale-the sort of thing that can only be done with the Harvard Business School's vast resources. It recalls an analogous study a quarter century ago, when several of us at Harvard studied the cost and schedule performance of advanced weapons systems research and development programs.

In a sense the results are remarkably similar. Dredging up my old records, I regressed the cost overrun factors for eleven weapons development programs on an index of relative technical difficulty, which is analogous to the authors' product complexity variables. Emulating their procedure, I then regressed the residuals from that regression on a variable measuring the degree to which the actual $R \& D$ time schedule departed from the schedule originally planned. The simple correlation coefficients ranged between .64 and .67 , depending on whether the analysis was linear or logarithmic. Kim Clark and his colleagues find a correlation of .69 between engineering hours and lead time. They draw almost the same inference from their results as Merton Peck and I did: if schedules are kept under control, cost overruns also tend to be restrained. ${ }^{1}$

As the authors recognize, these results do not refute the notion of a time-cost trade-off. Rather, the results suggest that it is a ceteris paribus relationship, and the "other things" are undoubtedly much more important to project outcomes than movements along the curve. Organization appears to matter, and so also may interorganizational differences in efficiency.

Why should such large differences in the quality-adjusted cost of product development exist and persist among manufacturers in different countries? And why don't all companies adopt the use of a strong product manager for organizing development efforts, since such an approach seems to be a successful strategy? The advantages of the project manager

1. Merton J. Peck and Frederic M. Scherer, The Weapons Acquisition Process: An Economic Analysis, vol. 1 (Harvard University, Graduate School of Business Administration, 1962), p. 441. 
in complex developments were well known and widely touted twentyfive years ago, when Peck and I did our research on weapons development. Clark and his colleagues have not provided clear answers, nor can I. I do, however, have some hypotheses.

First, inefficient development organizations survive because they are not subjected to strong market tests. They do not sell products in competititon with other groups. Instead, they transfer complex, everchanging services internally within a large organization. From the authors' analysis of the payoffs attributable to completing a car development four months ahead of schedule, it would appear that the quasirents generated by those services far exceed the costs, so development activities, too, are not subjected to a tough internal test when the question is asked, "Is this activity worth doing?"

Parkinson's first law is especially applicable in engineering development organizations. One of the lessons I absorbed during the Harvard weapons project was that if one employs an engineer and tells him to engineer, he will find things to do, whether they are needed or not. His output in turn becomes input for other engineers. Yet we saw weapons development groups in which the law did not hold. They were almost uniformly organizations that for one reason or another had more projects than they could accommodate, leading me to generalize:

Under conditions of high opportunity cost, firms have a kind of automatic contractual incentive for efficiency. ... That is, if a firm with high opportunity costs uses fewer scientists, engineers, project managers, and skilled production workers on one development contract, it can employ those persons to obtain and execute other development contracts which yield additional profit. ...2

I have always believed this was one of the most important lessons taught by our research. Failure to heed it and to load good defense contractors heavily is a major reason why weapons programs cost so much. The authors here suggest some support for the generalization by noting that in Japan, chronic shortages of engineers placed sharp limits on specialization while competition motivated efficient use of engineers.

Parkinsonian tendencies toward overstaffing may be especially prevalent in very large, mature parent organizations. Here too, there is outside supporting evidence. Arnold Cooper conducted a smaller-scale

2. Frederic M. Scherer, The Weapons Acquisition Process: Economic Incentives, vol. 2 (Harvard University, Graduate School of Business Administration, 1964), p. 185. 
study similar to that of the authors. ${ }^{3}$ Investigating products that had been developed independently and almost simultaneously in two firms, one large and one small, he found that the large firm spent from three to eight times more to develop essentially identical products. From interviews he inferred that the small firm was more efficient because it was more cost-conscious, enjoyed closer communication among both R\&D and production staff, employed better-quality people, and had an atmosphere generally more conducive to efficient production.

One thing the authors do not tell us is whether there might have been discernible quality differences among the staffs employed in the various auto companies. It is said that the U.S. defense-space effort has drained away the top engineering talent from industries such as automobiles. Could this help explain the high cost of U.S. engineering efforts?

Motivation may also matter. David Halberstam revealed extreme demoralization among product engineers in U.S. auto companies as their technically advanced proposals were repeatedly rejected by financeoriented executives. ${ }^{4}$ In Japan, more prestige attaches to technical virtuosity. Could this be part of the explanation?

Why strong project managers were not employed might have a similar rationale. My observation suggests that organizational structures adapt to the strengths and weaknesses of the people at hand and do not simply follow lines drawn arbitrarily on organization charts. Did the U.S. and European auto companies lack strong individuals to emerge as project managers and product champions? Or was there something in the internal organizational politics that discouraged granting substantial authority to middle-level managers? Or did top management simply believe that functional organization permits fuller staff utilization at slack times (probably true) and therefore that the functional approach was less costly (a probable non sequitur)?

Finally, a technical note. The method used by the authors to adjust their raw data on engineering hours for work contracted outside seems intrinsically plausible. However, some results from my study of U.S. $\mathrm{R} \& \mathrm{D}$ and patenting suggest a caveat. In automobile assembly, 0.28 invention patents were obtained per $\$ 1$ million of $1974 \mathrm{R} \& \mathrm{D}$; in auto

3. Arnold C. Cooper, "R\&DIs More Efficient in Small Companies," Harvard Business Review, vol. 42 (May-June 1964), pp. 75-83.

4. David Halberstam, The Reckoning (William Morrow, 1986). 
parts, 4.35 patents were obtained.5 Clearly, the partsmakers' work is more inventive in the conventional sense. Could this mean that relatively more weight should be given to work that is contracted out? Or alternatively, could the higher outside invention rate per unit of input, demonstrating greater partsmaker efficiency, imply an adjustment less than proportional to physical task assignment levels?

The research presented in this paper is an impressive first step. I hope its continuation will provide answers to some of the questions I raise as well as to the many other questions that will undoubtedly emerge in the discussion.

\section{General Discussion}

Kim Clark agreed with John Meyer's point that the starting position and the historical experiences of the individual firms are important in explaining their different organizational styles and performances, noting that the historical prevalence of functional organizations in Europe and the United States may have to do with the fact that functional organizations are easier to manage.

With regard to starting point, Timothy Bresnahan noted that all the projects studied were begun during or just after the second oil shock in the late 1970s. At that time U.S. firms were just beginning to gain experience in designing small, fuel-efficient cars, while Japanese and European firms were starting projects after a long history of building small cars. Hence it may be inappropriate to give the "Japanese effect", a structural interpretation. Clark responded that the selection process used for the projects should have controlled for some of the effects Bresnahan was concerned about. Every project studied, he said, was at least one generation removed from the first major new model line that represented a response to oil price increases, and in most cases the projects were two or three generations removed.

Edwin Mansfield pointed out that the industrial context is also important. In a comparative study of cost and time required for product imitation by Japanese and U.S. companies, he found that the perfor-

5. F. M. Scherer, “The Propensity To Patent," International Journal of Industrial Organization, vol. 1 (March 1983), pp. 107-28. 
mance advantage of Japanese firms was particularly strong in machinery, electrical equipment, and instruments industries, but negligible in chemicals and drugs. Moreover, the Japanese advantage was greater in innovations that represented relatively modest adaptations and improvements rather than major innovations based on internally developed technologies. On these counts, the innovations studied in this paper happened to be ones in which the Japanese tend to excel. Hence, Mansfield cautioned that it would be a mistake to generalize too broadly from the authors' findings.

George Eads observed that General Motors had used a small-team organizational form similar to the authors' heavyweight structure in the 1950s to develop several of GM's more successful product lines, and that the company was again moving in that direction. Thus, GM's own experience gave credence to the authors' results. F. M. Scherer pointed out that the nature of the interaction between development and production teams was an important consideration in the choice of organizational structure. For example, he noted, the heavyweight team structure was similar to "skunk works" used to develop military systems and hardware. The success of such an approach depends on the existence of a highly skilled production staff that can work with less-than-perfect designs.

Clark agreed that this interaction is critical, but noted that in many instances the U.S. and European firms used some of the same suppliers of dies and other tooling that the Japanese used. Even when the highest level of production skill was available to the U.S. and European firms, however, their internal style of operations seemed to inhibit them from exploiting it. Instead, the Japanese suppliers adapted to the American model. Bruce Chew noted that the Japanese projects were placing more complete designs, with fewer errors, in the hands of their production people.

Thomas Kochan also took issue with the notion that lack of skill at the production phase would tend to cause U.S. firms to overdesign. Instead, he blamed overspecialization and overly rigid work organizations. Opening up the production process might enable the production work force to solve more problems on its own, which would have benefits in the design phase. People's skills are embedded in the structure in which they are organized, he said. 
Eads observed that the kind and form of the information being passed between various parties in a project affect the extent to which activities can be overlapped. Simultaneous engineering, for example, is facilitated by use of computer-aided design and mathematical modeling, since all the parties working on a project can have access to the most current model as their point of reference.

Clifford Winston raised a question about the appropriateness of the authors' implied structural model in which the price of the automobiles was an explanatory variable determining engineering hours. He suggested that both variables should be simultaneously determined and endogenous. Clark agreed that this was a problem, noting that a major part of the analytical problem facing the researchers involved deciding what variables should be regarded as measures of outcome and which ones were under the control of the firm and should be regarded as decision variables. Martin Baily wondered why the organizational differences persisted if some strategies had been so cleariy shown to be effective and questioned whether the differences were themselves a function of variables such as firm size and market structure. Chew responded that the authors had looked at these variables, which economists have traditionally used to explain differences in performance between firms, but found that they were not very powerful in explaining what was going on. Clark added that the project represented an attempt to get inside the black box of the firm, as economists traditionally view it. Their results, he concluded, are evidence that internal differences between firms are important, and they raise questions about why they exist, where they come from, and why they persist. 